\title{
Subcutaneous Sustained-Release of Poly-Arginine Ameliorates Cognitive Impairment in a Transgenic Mouse Model of Alzheimer's Disease
}

\author{
Gennadiy Fonar ${ }^{* *}$, Baruh Polis $^{1 *}$, Tomer Meirson${ }^{1}$, Alexander Maltsev ${ }^{2}$, Abraham 0. Samson ${ }^{1}$ \\ ${ }^{1}$ Faculty of Medicine in the Galilee, Bar Ilan University, Safed, Israel \\ ${ }^{2}$ Institute of Higher Nervous Activity and Neurophysiology, Russian Academy of Sciences, Moscow, Russia \\ Email: "fonar_g@yahoo.com
}

How to cite this paper: Fonar, G., Polis, B., Meirson, T., Maltsev, A. and Samson, A.O. (2018) Subcutaneous Sustained-Release of Poly-Arginine Ameliorates Cognitive Impairment in a Transgenic Mouse Model of Alzheimer's Disease. Advances in Alzheimer's Disease, 7, 153-182. https://doi.org/10.4236/aad.2018.74011

Received: October 20, 2018

Accepted: December 17, 2018

Published: December 20, 2018

Copyright $\odot 2018$ by authors and Scientific Research Publishing Inc. This work is licensed under the Creative Commons Attribution International License (CC BY 4.0).

http://creativecommons.org/licenses/by/4.0/

\section{(c) (i) Open Access}

\begin{abstract}
Poly-arginine peptides are a promising class of bioactive compounds that are capable of crossing the blood-brain barrier (BBB) and present neuroprotective properties. In this study, we test the activity of poly-arginine peptides in a triple-transgenic mouse model of Alzheimer's disease. To identify the best candidate, we examined the relative neuroprotective efficacy of the compounds with various lengths (R7, R9, and R11) via assessment of memory acquisition, long-term hippocampal potentiation (LTP), and cytotoxicity. Also, we explored the expression profiles of hundreds of key cell signaling proteins, and perform a high content antibody microarray comparative analysis of brain samples. The chronically treated animals with poly-arginine R9 show significantly improved acquisition of memory. This compound rescues hippocampal LTP deteriorated by $\mathrm{A} \beta$ at a better rate than other agents tested in this study and induces cellular pathways involved in neuroprotection and neuroplasticity. The treatment escalates the expression levels of Synapsin Ia in the mice hippocampi; however, it has no significant effect upon the rate of beta-amyloidosis. Poly-arginine R9 peptide is a well-tolerated compound that crosses the BBB and presents unique neuroprotective qualities. The substance halters the development of $\mathrm{AD}$ symptoms in a murine model and can be recommended for clinical investigation.
\end{abstract}

\section{Keywords}

L-Arginine, Memory, LTP, Amyloid Beta, Cytotoxicity, Apoptosis

${ }^{\star}$ These authors contributed equally to this work. 


\section{Introduction}

$\mathrm{AD}$ is a slowly progressive neurodegenerative disorder with an insidious onset. The incidence of the disease is prevalent among elderly people and women [1]. It is the most common cause of dementia accounting for $60 \%-80 \%$ of all cases. The disease disseminates by epidemical pace and afflicts already more than 47 million people worldwide [2]. The global cost of dementia is estimated to reach one trillion USD by 2018 [3], making the social burden and the significance of the problem comparable to cancer [4]. Recent progress in standard medical care led to the considerably longer expectancy of life and subsequently augmented AD morbidity.

Despite the latest advancements in general medicine, there is no efficacious treatment to treat the disease. Various complications have halted the development of an effective treatment. A continuing "challenge" is the delivery of potential agents through the BBB. The molecular weight of small-molecules transported into the brain through the $\mathrm{BBB}$ is less than $400-600 \mathrm{Da}$ [5]. In the present study, polypeptides R7-R11, with molecular weights ranging from 1219.4 to $1916.2 \mathrm{Da}$, were applied subcutaneously. Recent findings suggest that poly-arginine peptides are capable of in vivo general delivery to the brain by passing through the BBB. One in vivo kinetic study investigating the efficiency of R11-mediated peptide delivery in the normal and ischemic rodent brain demonstrates that the peptide appears in the microvessels and the surrounding neurons of the brain one hour after its systemic administration [6]. The signal of the peptide fades after two hours; however, in a transient middle cerebral artery occlusion mouse model, the R11 signal is enhanced and remains detectable in the cells, on the ipsilateral side, for as long as 8 hours after administration compared to the contralateral side.

There has been a growing interest in various bioactive compounds containing poly-arginine in recent years, and several studies have demonstrated their potent neuroprotective properties [7]. Reliable data has been acquired in in vitro glutamate excitotoxicity neuronal injury models, and in vivo in animal stroke models indicating that positive peptide charge and arginine residues are critical for neuroprotection [8]. It was established that poly-arginine peptides are highly neuroprotective, and their efficacy is positively correlated with increasing arginine content. In particular, it was postulated that for maximum neuroprotection, approximately 15 arginine residues are required. According to the authors, poly-arginine reduces intracellular neuronal calcium levels when administered before glutamic acid exposure.

Currently, the precise mechanism of neuroprotection mediated by arginine-rich compounds has not been elucidated completely. There is evidence that poly-arginine R6 can interfere with cell surface ion channels and, particularly, with NMDA receptors [9]. Marshal et al. elegantly demonstrated that poly-arginine R7 and its derivatives are capable of blocking NMDA-induced caspase activation in the intact retina [10]. According to the authors, inhibition of NMDA-induced 
retinal neuronal death by poly-arginine peptides is associated with the attenuation of stress-induced hyperpolarization of the inner mitochondrial membrane potential. The authors observed a concentration-dependent decrease in mitochondrial respiration in the presence of $\mathrm{R} 7$ and hypothesized that the neuroprotection provided by the peptide is the result of its affinity for targeting the mitochondria and subsequent decrease of the resting mitochondrial membrane potential $(\Delta \Psi \mathrm{m})$. Remarkably, a significant reduction of ROS production by poly-arginine was detected without exogenous stress. Even though the mitochondrial target of poly-arginine remains unidentified, the authors speculate that the guanidinium groups in the poly-L-arginine peptide act in a similar fashion to guanidinium-containing compounds, which play vital biological roles in mitochondria.

The aforementioned decrease of $\Delta \Psi \mathrm{m}$ appears to be essential for prevention of apoptosis in various neurodegenerative diseases and AD particularly [11]. Mitochondrial membrane hyperpolarization leads to excessive ROS production and consequential cell death. Mitochondrial function impairment, in general, is believed to play a prominent role in the pathogenesis of $\mathrm{AD}$, and some authors identify mitochondrial dysfunction as a trigger for AD pathophysiology [12] [13].

Even though there is no consensus in the scientific literature about the precise mechanism of the neuroprotective effects of poly-arginine peptides, recent data demonstrate that they are capable of moderating a calcium influx, which might be destructive and extremely detrimental to cell survival [14]. Additionally, MacDougall et al. have proved that application of poly-arginine R12 peptide diminishes the expression of the glutamate receptor subunit NR2B upon neuronal cell surface [15]. The authors have not identified the mechanisms responsible for NR2B downregulation; however, speculate that endocytic processes could not be ruled out.

We believe that the neuroprotective effect of arginine-rich peptides can be potentiated by their short derivatives, including L-arginine itself, which is a semi-essential amino acid. It was evidenced that the postmortem brains of AD patients demonstrate a moderate decrease in L-arginine levels [16]. Therefore, arginine deficiency might be associated with the neurodegenerative progress of the disease. It was confirmed that L-arginine administration within 30 minutes of a stroke significantly decreases the frequency and severity of stroke-like symptoms [17]. Noteworthy, $1.6 \mathrm{~g}$ of L-Arginine supplemented daily for three months in the diet of patients with senile dementia increased cognitive function by about $40 \%$ [18]; however, the effect of the drug did not last after the cessation of the treatment.

In humans, L-arginine is transported from the circulating blood into the brain via the $\mathrm{Na}^{+}$-independent cationic amino acid transporter (CAT1) expressed at the BBB [19]. It was demonstrated that the L-arginine influx transport in the rat $\mathrm{BBB}$ is saturable with a Michaelis-Menten constant $(\mathrm{km})$ value of $56 \mu \mathrm{M}$. However, 
the physiological serum concentration of L-arginine is significantly higher in rodents (about $170 \mu \mathrm{M}$ ) and humans (about $100 \mu \mathrm{M}$ ) [20]. Moreover, L-arginine in mammals is derived mostly from the renal de novo synthesis and dietary intake, so CAT1 at the BBB represents a sole supply pathway for the amino acid to the brain [21]. Despite the ability of arginine to pass the $\mathrm{BBB}$, the capacity of its transporter is limited [22]. Therefore, the transport of L-arginine via the BBB by poly-arginine peptides is an interesting conduitto supply more arginine and its derivatives to the brain.

Our group has previously shown that intracerebroventricular administration of L-arginine significantly improves spatial memory acquisition in 3xTg-AD mice, without a considerable reduction of the rate of $\beta$ amyloidosis. L-arginine shows little or no impact on long-term potentiation (LTP) and does not rescue LTP deterioration induced by $\mathrm{A} \beta$, nevertheless, induces cellular pathways involved in neuroprotection, including oxidative stress protection, and defense response [23].

In line with recently published studies demonstrating promising neuroprotective properties of poly-arginine peptides, we designed an experiment investigating and expanding a potential spectrum of use for these compounds with an accent upon neurodegenerative disorders. We tested and compared the activity of different poly-arginine peptides in a rodent model of $\mathrm{AD}$.

Significantly improved acquisition of memory of the animals treated chronically with poly-arginine R9 has been proven in a behavioral paradigm. Electrophysiological data support the hypothesis that poly-arginine R9 peptide facilitates the hippocampal LTP deteriorated by A $\beta$ (25-35) oligomers. Moreover, we show that treatment of $3 \times \mathrm{Tg}-\mathrm{AD}$ mice with poly-arginine $\mathrm{R} 9$ regulates several critical biological processes.

\section{Materials and Methods}

\subsection{Mouse Strains}

Triple-transgenic mice (3xTg-AD) is a widely used animal model of AD containing three mutations associated with familial Alzheimer's disease (APP Swedish, MAPT P301L, and PSEN1 M146V). The mice exhibit synaptic deficiency with both plaque and tangle pathology [24]. The animals were purchased from the Jackson Laboratory ${ }^{\circledast}$ and bred in our animal facility. Forty age-matched 6.5 months old female mice with an average weight of 33 grams were used for all experiments. Female 3xTg-AD mice are known to react to the treatments in superior manner than males (Salvatore Oddo, personal communication).

All experimental protocols were performed in accordance with the instructions of the Israeli Ministry of Health's Council for Experimentation on Animals and with Bar Ilan University guidelines for the use and care of laboratory animals in research, supervised by the institutional animal care and use committee. The experimental protocol was approved by the Committee on the Ethics of Animal Experiments of the Bar Ilan University (Permit Number: 3-01-2017). 
Before and during the experiment, mice were socially housed in standard plastic cages in humidity $(30 \%)$ and temperature $\left(22^{\circ} \mathrm{C}\right)$ controlled room with a 12-h reverse light/dark cycle. The animals were provided with water and food ad libitum.

Mice received a unique identity number (ear tag) and were randomized to individual four experimental groups of 10 mice each (a control group with PBS administration, and three experimental groups, treated with a various poly-L-arginine solution in PBS). Body weight was monitored weekly throughout the experiment.

All peptides were purchased from GL Biochem (Shanghai) Ltd. with a purity higher than 95\%. The peptides were dissolved in PBS ( $\mathrm{pH} 7.4$ ) with a concentration of $20 \mathrm{mM}$ and loaded into the Alzet $^{\circledast} 1004$ pump capsules, which deliver $0.11 \mu \mathrm{L} / \mathrm{h}$. The peptides used in this study are listed in Table 1 .

\subsection{Drug Administration and Surgical Procedure}

Poly-L-arginine peptides and saline control solutions were administered subcutaneously using osmotic minipumps. First, the animals were anesthetized with $1 \%$ isoflurane. A spinal subcutaneous pocket for the Alzet ${ }^{\circledast}$ pump capsule was made with a pair of scissors Then, preactivated during 24 hours in DDW osmotic minipump (Alzet, model 1004, 28 days delivery) prefilled with $100 \mu$ of poly-L-arginine $(20 \mathrm{mM})$ in $\mathrm{PBS}$ or $\mathrm{PBS}$ at $\mathrm{pH} 7.4$ has been placed in the pocket and the surgical cut was stapled (AlzetAutoClip). The dose of the substance was calculated in accordance with the previously published data, where rats were administered intravenously with $100 \mathrm{nM} / \mathrm{kg}$ and up to $1 \mu \mathrm{M}$ of R18 without any side-effects (single injection) [25]. The dose of $300 \mathrm{nM} / \mathrm{kg}$ was used in other studies [26]. We applied a slow-release technology and delivered about $63 \mathrm{nM} / \mathrm{kg}$ per hour, which is $1.51 \mu \mathrm{M} / \mathrm{kg}$ per day (taking into account the average weight of the animals about $35 \mathrm{gr}$ at the end of the experiment). The timeline of the experiment is presented in Figure 1.

\subsection{Behavioral Tests}

\subsubsection{Contextual Fear Conditioning}

Contextual fear conditioning is a basic conditioning procedure and a simple form of associative learning, in which an animal learns to associate the presence of a neutral stimulus, termed the conditioned stimulus, such as a light or a tone, with the presence of a motivationally significant stimulus, termed the unconditioned stimulus, such as an electric shock [27]. In this paradigm, the freezing

Table 1. Poly-L-arginine peptides used in the study.

\begin{tabular}{cccc}
\hline Peptide & Sequence & Arginine residues/Amino acids & Net charge at $\mathrm{pH} 7$ \\
\hline R7 & RRRRRRR & $7 / 7$ & 7 \\
R9 & RRRRRRRRR & $9 / 9$ & 9 \\
R11 & RRRRRRRRRRR & $11 / 11$ & 11 \\
\hline
\end{tabular}




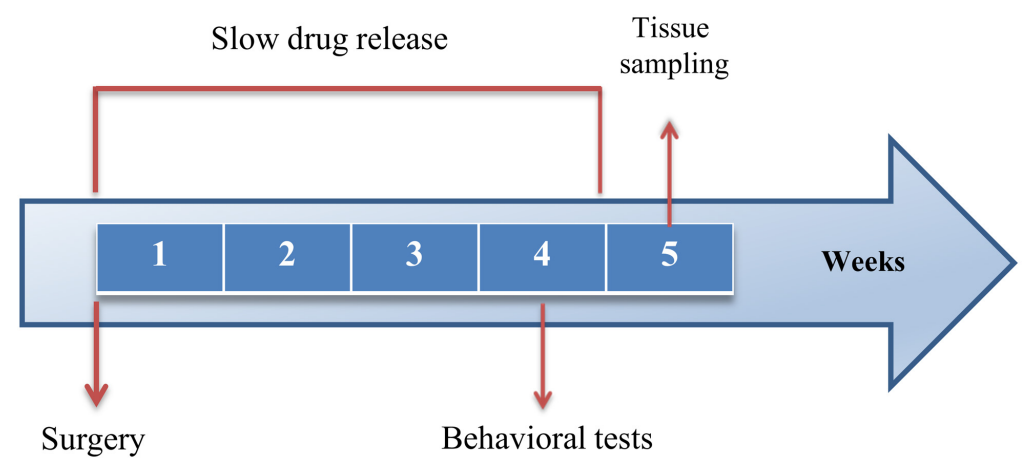

Figure 1. Experimental design. The schematic timeline of the experiment.

behavior represents a typical natural response in rodents. The easily assessable lack of movement provides a readout of the memory acquisition and reflects the integrity of the hippocampus [28].

The experiments were performed using two standard chambers with shock floors purchased from Noldus ${ }^{\oplus}$. Each chamber has a $17 \times 17 \mathrm{~cm}$ floor and is $30 \mathrm{~cm}$ in height and is equipped with a top unit including a matrix of infrared LED lights and an infrared CCD camera, with a high-pass filter blocking visible light. The floor of a chamber includes a stainless steel grid (inter-bar separation $0.9 \mathrm{~cm}$ ) connected to an electric shock generator controlled by a special software. Automated tracking was done with EthoVision XT 10 software provided by Noldus ${ }^{\oplus}$. Mice were handled for three successive days for 5 min a day. During the first day, an animal was placed in a chamber for five min and exposed to white background noise. On the second day of a conditioning session, mice received three $2 \mathrm{sec}$ long $0.75 \mathrm{~mA}$ foot shocks, at 2.5, 3.5, and $4.5 \mathrm{~min}$ after placement into the chamber. On the third day of the testing session, mice were exposed for five min to the same conditioning context without a shock. EthoVision software controlled the shock periods and amplitude, and the experimental parameters such as trial time and testing zones via user predefined variables. Conditioned freezing was defined as immobility except for respiratory movements. For statistical analysis of the data, a one-way analysis of variance (ANOVA) with post hoc analysis comparing the various treatment groups using the raw freezing scores of the contextual freezing has been used.

\subsubsection{Open-Field Experiment}

The open-field experiment was designed to test the effects of poly-arginine peptides or vehicle upon the locomotor activity of the animals. The paradigm is one of the most know tests to assess exploration and locomotion [29]. The open field maze measured $40 \mathrm{~cm}$ (length) $\times 40 \mathrm{~cm}$ (width) $\times 40 \mathrm{~cm}$ (height) and made from white high-density, and non-porous plastic was used. The testing was performed in a standard lit room. The video tracking camera and EthoVision XT 10 software from Noldus ${ }^{\oplus}$ were applied to record and evaluate mouse movement.

The animals were allowed to acclimate to the procedure room for a minimum of $30 \mathrm{~min}$ before the test. A mouse was removed from the home cage by gently 
grasping its tail and placed in the middle of the maze. It was allowed free and uninterrupted movement for $10 \mathrm{~min}$. The total distances traveled in the maze were statistically analyzed by analysis of variance, followed by post-hoc Bonferroni test performed on SPSS 22.0.

A Panasonic WV-CL930 camera with the Ganz IR 50/50 Infrared panel recorded all behavioral experiments. The recorded video files were coded and analyzed with the Ethovision XT 10 software (Noldus ${ }^{\circledR}$ ) by a blind to the treatment schedule experimenter.

\subsection{Electrophysiology}

To study the synaptic plasticity, we applied electrophysiological techniques. Seven male seven months old C57BL/6 mice were anesthetized with isoflurane and decapitated. Brains were quickly removed and submerged in ice-cold dissection solution (concentrations in mM: $124 \mathrm{NaCl}, 3 \mathrm{KCl}, 1.25 \mathrm{NaH}_{2} \mathrm{PO}_{4}, 26$ $\mathrm{NaHCO}_{3}, 1.3 \mathrm{CaCl}_{2}, 7 \mathrm{MgCl}_{2}$, and $10 \mathrm{D}$-glucose, $\mathrm{pH}$ equilibrated, with $95 \% \mathrm{O}_{2}-$ $\left.5 \% \mathrm{CO}_{2}\right)$. Transverse hippocampal slices (350 $\mu \mathrm{m}$ thick) were prepared using a vibratome (Leica VT1000S, Germany). The slices were randomly assigned to control and treatment groups and immediately transferred to a recording solution (composition as above, except the $\mathrm{CaCl}_{2}$ and $\mathrm{MgCl}_{2}$ concentrations, were adjusted to 2.5 and $1.3 \mathrm{mM}$, respectively). Slices were heated to $36^{\circ} \mathrm{C}$ in a water bath for $40 \mathrm{~min}$ and then kept at room temperature. Amyloid $\beta$ peptide (25 - 35) was dissolved in $\mathrm{mQ}$ water to $1 \mathrm{mM}$ stock solution and frozen. $24 \mathrm{~h}$ before the experiment, the $\mathrm{A} \beta$ peptide was dissolved to $50 \mathrm{nM}$ in artificial cerebrospinal fluid (ACSF) and incubated at $+4^{\circ} \mathrm{C}$ for oligomerization. Slices were incubated for 1 hour with control ACSF, $100 \mu \mathrm{M}$ of various poly-arginine peptides or mixture of $50 \mathrm{nM} \mathrm{A} \beta(25$ - 35) and the peptides before transferring to the recording chamber. During the experiments, slices were perfused by a continuously flowing (appr. $4 \mathrm{ml} / \mathrm{min}$ ) recording solution at $\sim 33^{\circ} \mathrm{C}$. Electrophysiological recordings were carried out using SliceMaster system (Scientifica, UK). Field excitatory postsynaptic potentials (fEPSP) were recorded from stratum radiatum in area CA1 using glass microelectrodes (1 - $2 \mathrm{M} \Omega$ ) filled with the recording solution. Baseline synaptic responses were evoked by paired-pulse stimulation with $50 \mathrm{~ms}$ interval of the Schaffer collaterals at $0.033 \mathrm{~Hz}$ with a bipolar electrode. Test stimulation intensity was adjusted to evoke fEPSP with amplitude $50 \%$ of maximal and was kept constant throughout the experiment. LTP was induced with four $100-\mathrm{Hz}$ trains spaced $5 \mathrm{~min}$ apart. The data were recorded and analyzed by Spyke 2 (Cambridge Electronic Design Ltd.) and SigmaPlot (Systat Software Inc.). For baseline responses analysis fiber volley amplitudes and appropriate fEPSP slopes during test stimulation were evaluated. LTP is expressed as the mean \pm SEM\% of baseline fEPSP slope. Statistical comparisons used two-way ANOVA with post hoc Bonferroni test.

\subsection{Cell Culture}

Rat pheochromocytoma-derived PC12 cells are widely used in studies of neuro- 
toxicity and apoptosis assays [30]. The line has been commonly used in numerous investigations of potential neuroprotective agents to treat neurodegenerative diseases, such as Huntington's disease, Parkinson's disease, and AD [31] [32].

The cell line (\#88022401) was obtained from Sigma ${ }^{\oplus}$. The cells were maintained in DMEM medium supplemented with $10 \%$ fetal bovine serum, $5 \%$ horse serum, $100 \mathrm{U} / \mathrm{mL}$ penicillin and $100 \mu \mathrm{g} / \mathrm{mL}$ streptomycin at $37^{\circ} \mathrm{C}$ in a humidified $95 \%$ air $/ 5 \% \mathrm{CO}_{2}$ incubator.

\subsection{Peptide Cytotoxicity Test}

R9 peptide cytotoxicity was evaluated by exposing PC-12 cells to a medium containing various peptide concentrations for 48 hours. R9 peptide was prepared as a $1 \mathrm{mM}$ stock in sterile PBS, and then the solution was diluted to the required concentrations with serum-free DMEM. Cytotoxicity was assessed in MTT tests.

\subsection{Cell Viability Assays}

Cell viability was assessed by measuring formazan produced by the reduction of MTT. The MTT assay is a sensitive measurement of the normal metabolic status of cells, particularly those of mitochondria, which reflects early cellular redox changes. Therefore, the amount of formazan produced is proportional to the number of viable cells. Briefly, the cells were plated in 96 well poly-D-lysine-coated culture plates at the density of $1 \times 10^{4}$ cells/well at $37^{\circ} \mathrm{C}$ for 24 hours with media containing various concentrations of poly-arginine R9. The cells were treated with $400 \mu \mathrm{M}$ of $\mathrm{H}_{2} \mathrm{O}_{2}$ for more 24 hours. These concentrations of $\mathrm{A} \beta$ and $\mathrm{H}_{2} \mathrm{O}_{2}$ have been used previously in numerous studies to check the viability of PC-12 cells [33] [34]. Subsequently, MTT reagent (final concentration, $0.5 \mathrm{mg} / \mathrm{mL}$ ) was added to each of the wells, and the plate was incubated for three hours at $37^{\circ} \mathrm{C}$. At the end of the incubation, $100 \mu \mathrm{L}$ of DMSO were added to each well. The formazan reduction product was measured by reading absorbance at $590 \mathrm{~nm}$ in a microplate reader (Infinite ${ }^{\circledast} \mathrm{M} 1000$ ). Cell viability was presented as a percentage of the control culture.

\subsection{Immunohistochemistry and Image Analysis}

The whole animal perfusion of 10 animals (five from each group) with paraformaldehyde solution was performed in accordance with the standard protocol [35]. Brains were removed and placed in $4 \%$ paraformaldehyde (Sigma-Aldrich) for 24 hours at $4^{\circ} \mathrm{C}$, followed by a cryo-protective treatment for 48 hours in $30 \%$ sucrose (Sigma-Aldrich). Then the samples were snap-frozen and cut with a cryostat (Leica) into $30 \mu \mathrm{m}$ thick coronal sections. The sections were made through anterior (bregma; -1.00 to $-1.46 \mathrm{~mm}$ ), middle (bregma; -1.58 to $-2.30 \mathrm{~mm}$ ), and posterior hippocampus (bregma; -2.46 to $-3.16 \mathrm{~mm})$ of control $(\mathrm{n}=5)$ and poly-arginine treated mice $(n=5)$. The sections were blocked with $10 \%$ Normal Horse Serum (Vector) and $0.03 \%$ Triton $^{\mathrm{TM}} \mathrm{X}-100$ (Sigma-Aldrich) in PBS for one hour and stained with a primary monoclonal mouse $6 \mathrm{E} 10$ anti-amyloid $\beta$ antibody $(1: 100, \mathrm{ENCO})$ for $24 \mathrm{~h}$ at $5^{\circ} \mathrm{C}$, followed by washing and incubation for one 
hour with secondary antibody Alexa555 goat anti-mouse IgG (1:200, Invitrogen) for one hour and Hoechst (1:5000, Sigma) for three min. Sections were mounted and viewed under an Upright Microscope ApoTome (Quorum Technologies) with a mercury arc lamp and DAPI filter (excitation filter $=350 \mathrm{~nm}$ ) and two lasers (excitation $=491 \mathrm{~nm}$ and $561 \mathrm{~nm}$ ). Immunolabeling was examined in various corresponding cortical and hippocampal areas of the animals, and image analysis was performed with Zen Blue 2.5 (Zeiss) software.

\subsection{Tissue Sampling}

For brain tissue preparation, mice were deeply anesthetized with Zoletil (12.5 $\mathrm{mg} / \mathrm{kg}$ ), and Rompun mix (17.5 mg/kg) administered intraperitoneally and decapitated. Their brains (five from each group) were sliced (500 $\mu \mathrm{m}$ thick) immediately in the mouse brain slicer matrix. Tissue punches with $0.8 \mathrm{~mm}$ in diameter were taken from dentate gyri and frozen at $-80^{\circ} \mathrm{C}$.

\subsection{Antibody Microarray}

The assessment of "hit" proteins' expression was performed by the use of the Kinex KAM-1150E Antibody Microarray (Kinexus Bioinformatics Corp., Vancouver, B.C.), in accordance with the manufacturer specification. The analyses were done with hippocampal lysates of mice treated with poly-arginine R9 and PBS as described on Kinexus' web page (http://www.kinexus.ca/). Briefly, lysate protein from each sample $(100 \mu \mathrm{g})$ was labeled covalently with a fluorescent dye combination. Free dye molecules then were removed via gel filtration. After blocking non-specific binding sites on the array, an incubation chamber was mounted onto the microarray to permit the loading of 2 samples (one poly-arginine treated (pooled from five brains), and one vehicle treated (pooled from five braines). After the incubation, unbound proteins were washed away. Two 16-bit images have been captured by a ScanArray Reader (Perkin-Elmer) for each array. Antibody array was performed in parallel on four different chips. The output of the array contains the Average Normalized Net Signals, which is the average determined from the four Normalized Net Signal values that are available for each antibody on the microarray. Standard Deviation represents the standard deviation in the four separate measurements of the Globally Normalized Signal Intensity values for each different antibody on the microarray. Percent Standard Deviation is the percent standard deviation in the four separate measurements of the Globally Normalized Signal Intensity values for each different antibody on the microarray. Data are presented as change from control (CFC\%). Value of $100 \%$ corresponds to a 2 -fold increase in signal intensity with the treatment. A negative $\mathrm{CFC}$ value indicates the degree of reduction in signal intensity from the selected control.

Each parameter has its own Student T-Test p-value, which is the probability (p) value that there is no difference between the control and test samples. p-value determined with $\mathrm{N}=4$ measurements in each set, which are paired and two-tailed in distribution. A p-value of 0.05 or less is taken as a statistically valid 
change.

\subsection{Functional Interpretation of the Microarray Data with DAVID Bioinformatics Resources}

The microarray data were analyzed using DAVID Bioinformatics Resources web server for functional interpretation of gene lists. We used a list of priority genes, defined by at least $20 \%$ change compared to control and p-value $<0.05$ to identify significantly enriched KEGG, Reactome, and Biocarta pathways and GO (gene ontologies). Cytoscape and STRING (http://www.string-db.org) were used for topological analysis and network visualization of the identified terms.

\subsection{Western Blotting}

In order to study the influence of the treatment on the rate of beta-amyloidosis, we examined the A11 immunoreactivity of the hippocampal lysates. A11 is an antibody that detects the conformation of amyloid oligomers irrespective to their amino acid sequence [36]. The anti-amyloid antibody A11 NN198-1was used to identify oligomeric forms. To investigate the presynaptic component of neuroplasticity, we quantified the changes in the expression rate of Synapsin 1, which is associated with the synaptic vesicles neuronal phosphoprotein [37]. Antibody NN171-2 was selected to detect Synapsin isoform 1a.

Protein concentration was determined using the Bradford assay (Bio-Rad, Hercules, CA). Fifteen $\mu \mathrm{g}$ of pooled hippocampal lysates from five brains (each group) were analyzed by the KinetworksTM Custom Multi-Antibody Screen KCSS-1.0 (Kinexus Bioinformatics Corporation) as described by the manufacturer. Briefly, the KinetworksTM analysis involves resolution of a single lysate sample by SDS-PAGE and subsequent immunoblotting with validated antibodies. Antibodies bound to their target antigen on the nitrocellulose membrane are detected using the ECL Detection System.

\subsection{Statistical Analysis}

Statistical analyses were conducted using SPSS (version 22, IBM, Armonk, NY) for Windows. The significance was set at $95 \%$ of confidence. All results are presented as mean with standard error. Data were shown to fit a normal distribution using the Shapiro-Wilk test for normality, and Levene's test was used to confirm equal variance between groups being compared.

In regard to the behavioral tests, the means are compared between groups via a one-way ANOVA followed by post-hoc Bonferroni test. Viability data were analyzed by ANOVA, followed by post-hoc Bonferroni test, with $\mathrm{p}<0.05$ values considered statistically significant. Experiments were repeated independently at least two times. In LTP studies one-way ANOVA was used to determine the significant differences between the groups followed by Bonferroni's post-hoc for multiple comparisons.

All data are presented as mean values. Throughout the text and in bar plots, the variability is indicated by the standard error of the mean (SEM). 


\section{Results}

\subsection{Poly-Arginine Peptides Partially Rescue the A $\beta$ Mediated Hippocampal LTP Impairment}

Long-term potentiation (LTP) is an example of activity-dependent plasticity that was discovered in different regions of the brain and the hippocampus particularly. LTP is a valuable model of mnemonic processes, which helps to study various substrates of learning and memory acquisition [38]. It was shown by many groups that $\mathrm{A} \beta(25$ - 35) impairs hippocampal synaptic plasticity [39]. We applied the same model and examined LTP at Schaffer collateral-CA1 synapses. We first confirmed that treatment of wild-type mouse hippocampal slices with exogenous $\mathrm{A} \beta(50 \mathrm{nM})$ results in significantly impaired LTP in our recording conditions. In slices pre-treated with $\mathrm{A} \beta$, LTP was almost completely blocked (Figure 2(a)-(c)). To investigate the effect of various poly-arginine peptides on the rate of LTP and A $\beta$-induced LTP failure, the brain slices were treated with $100 \mu \mathrm{M}$ of R7, R9, and R11. In all cases, the normalized fEPSP slope was significantly reduced by the treatment with the agents. Remarkably, the influence of R11 peptide upon LTP was minimal compared to other compounds (about 16\% reduction only). The graph of $\mathrm{R} 11$ converges with the control during the entire time of the procedure (Figure 2(c)).

To examine a possible effect of poly-arginine peptides upon $\mathrm{A} \beta$ mediated hippocampal LTP impairment, we tested their effect in the presence of A $\beta$. R7 peptide treatment had no significant effect upon the rate of LTP, which was deteriorated by A $\beta$ treatment (Figure 2(a), Figure 3(b)). The effect of R9 and R11 treatment was significant $(\mathrm{p}<0.001)$, but R9 rescued LTP in a greater manner than R11 did. To visualize better the effect, we compared the distances of the recorded fEPSPs between the poly-arginine \& $\mathrm{A} \beta$ treated slices, and LTPs recorded from $\mathrm{A} \beta$ treated slices during periods of $30 \mathrm{~min}$ of the experiment. The same analysis was performed for LTPs recorded from the control slices without any treatment. R9 and $\mathrm{A} \beta$ treated slices demonstrated LTP, which was significantly ( $\mathrm{p}<0.001$ ) closer to the control, compared to R7 and R11. The summary of the analysis is presented in (Figure 3(a) and Figure 3(b)).

It seems that R9 poly-arginine possesses superlative protective properties. It rescues the $\mathrm{A} \beta$ mediated hippocampal LTP impairment in a superior manner compared to other tested compounds.

\subsection{Subcutaneous Chronic Administration of Poly-l-Arginine Peptide R9 Significantly Improves Memory Acquisition of 3xTg-AD Mice without Influencing upon Locomotor Activity}

The exploratory locomotor activity of the experimental animals was evaluated in the open field maze. We did not observe any significant effect of the treatment on the rate of the movements and total distance moved during the 10 min period (data not presented).

Contextual fear conditioning was applied to study the influence of the treatment on the rate of learning and memory functions in 3xTg-AD mice. Initial 


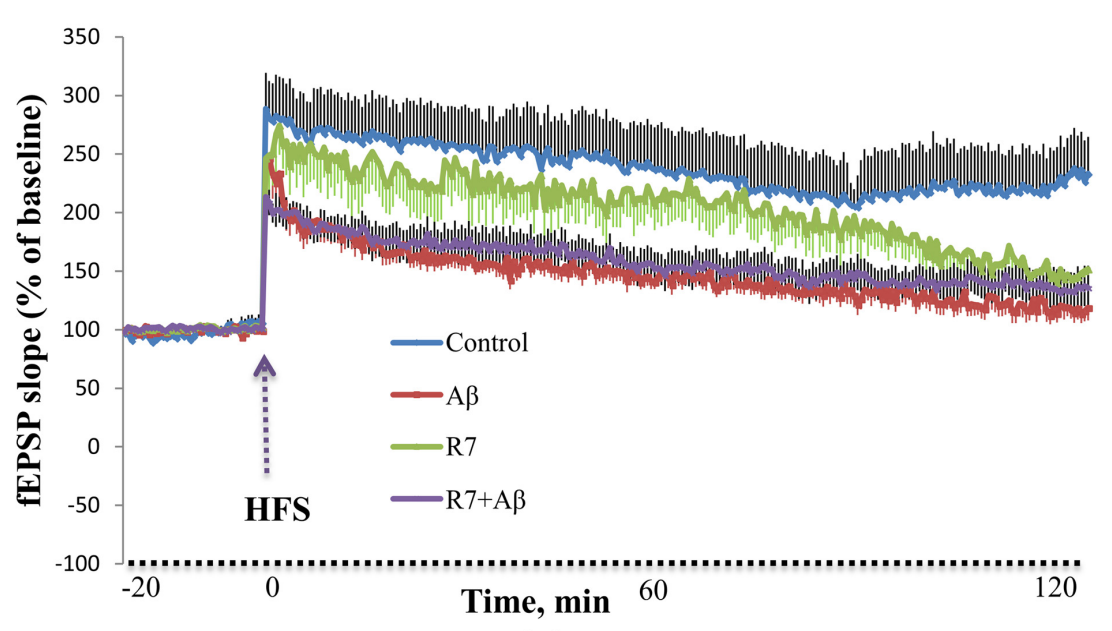

(a)

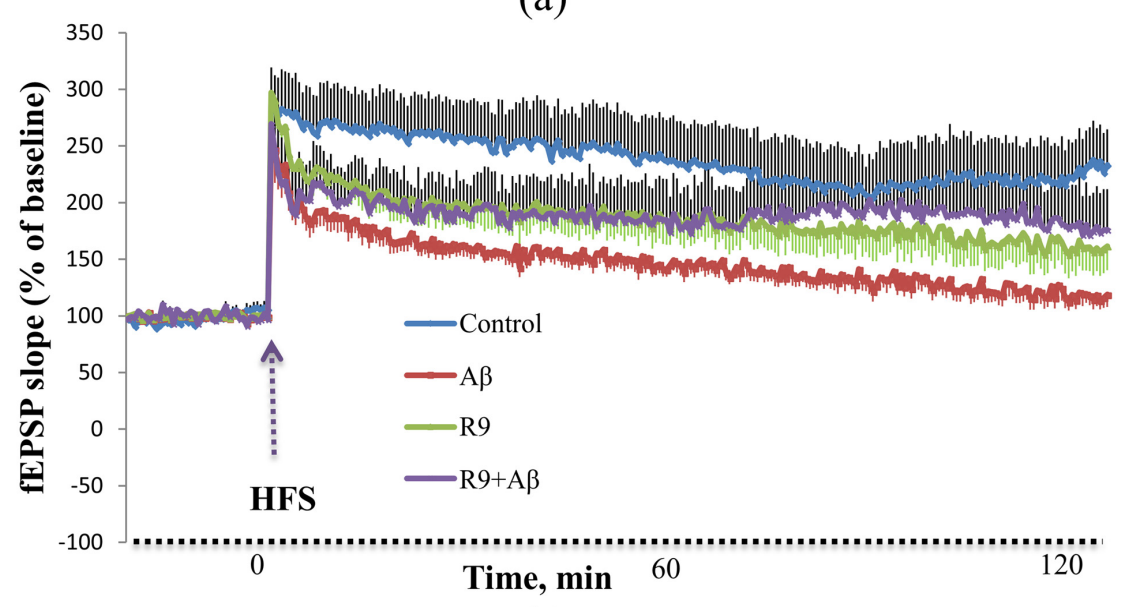

(b)

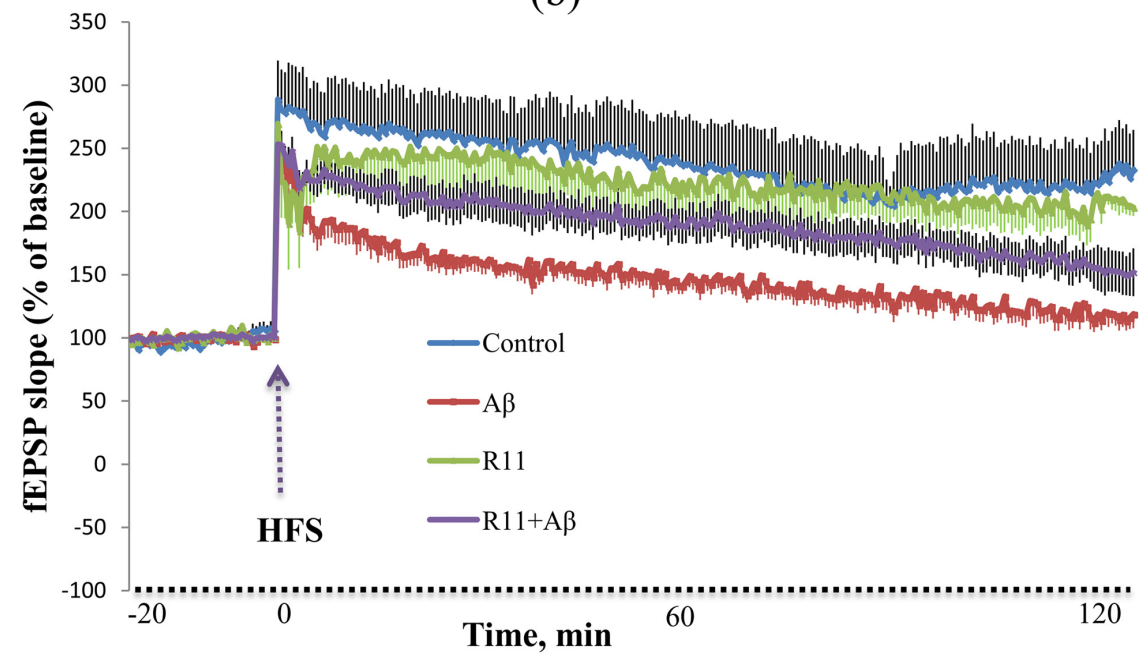

(c)

Figure 2. Hippocampal Schaffer collateral-CA1 LTP recorded in (a) R7 treated slices, (b) R9 treated slices, (c) R11 treated slices. Error bars are SEM, n = 7 .

habituation period on day 1 allowed acclimation to the experimental environment and reduction of orienting responses. There were no significant differences 


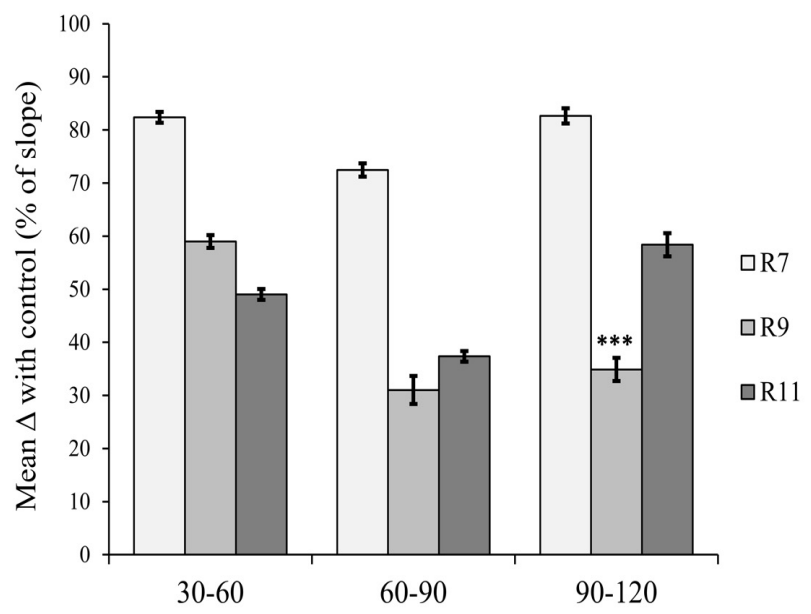

(a)

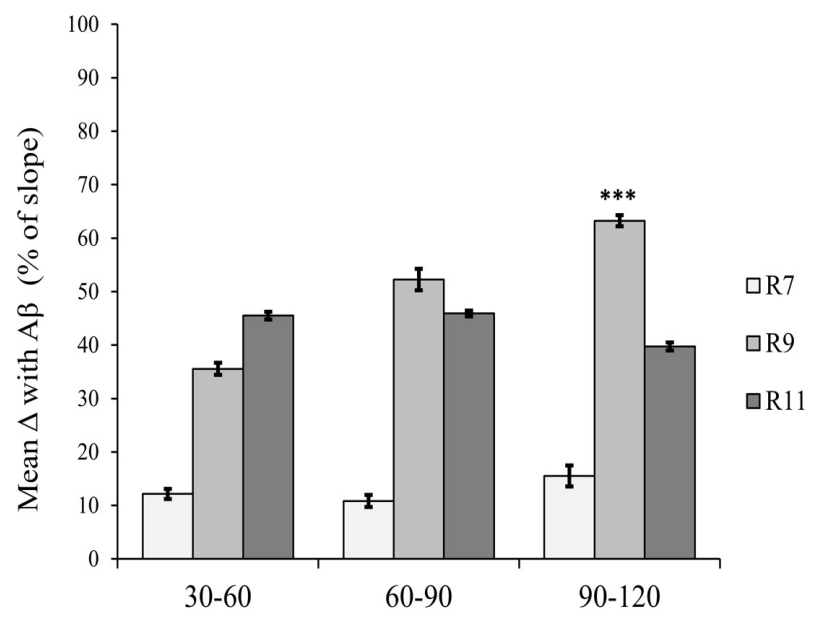

(b)

Figure 3. Differences between the normalized fEPSP slopes of the treated with various poly-arginine peptides, aged A $\beta$, and the control slices (a) just A $\beta$ treated slices (b) during $30-120$ min of the recording. Error bars reflect SEM. Statistical analysis of the very last $30 \mathrm{~min}$ period reveals a significant effect of the treatment upon the difference between the fEPSP slopes of $\mathrm{A} \beta$ and poly-arginine, $\mathrm{A} \beta$ treated slices as determined by one-way ANOVA $(\mathrm{F}(3,236)=1156.861, \mathrm{p}=0.000)$. The effect of R9 peptide was significantly $(\mathrm{p}<0.001)$ greater, by $25 \%-50 \%$, than the effect of other tested compounds.

in baseline freezing detected on this day. Freezing behavior of the mice was tested 24 hours after training. The animals treated with various poly-arginine peptides exhibited increased freezing time compared to the control group (Figure 4). However, only the treatment with R9 peptide demonstrated a significant effect.

\subsection{Poly-Arginine R9 Is Not Toxic but Protective against Hydrogen Peroxide-Induced Cytotoxicity in Cultured PC-12 Cells}

We first examined the cytotoxic effect of different concentrations $(5,10$, and $50 \mu \mathrm{M})$ of R9 peptide in PC-12 cultures following a 48-h exposure duration (Figure $5(a))$. The exposure caused no any significant increase in cell death compared to the untreated cultures.

To study the effect of poly-arginine R9 upon cell viability in the $\mathrm{H}_{2} \mathrm{O}_{2}$-stressed cultured PC12 cells, the cells were preincubated for 24 hours with various concentrations of the peptide and stressed with $400 \mu \mathrm{M} \mathrm{H} \mathrm{H}_{2} \mathrm{O}_{2}$ for additional 24 hours. The treatments induced morphological dose-dependent alterations, which are apparent under a light microscope (data not shown). The relative rate of induced cell death was evaluated by MTT assay.

As shown in (Figure 5(b)), incubation of the cells with $400 \mu \mathrm{M} \mathrm{H}_{2} \mathrm{O}_{2}$ during 24 hours leads to a decline of viability rate, which is partially reversed by supplement of the R9 peptide to the medium.

It was demonstrated previously in another in vitro model of cytotoxicity that five $\mu \mathrm{M}$ of $\mathrm{R} 9$ provides a sufficient protective effect, which is not significantly different from $10 \mu \mathrm{M}$ [8]. Our findings accord with this result. 


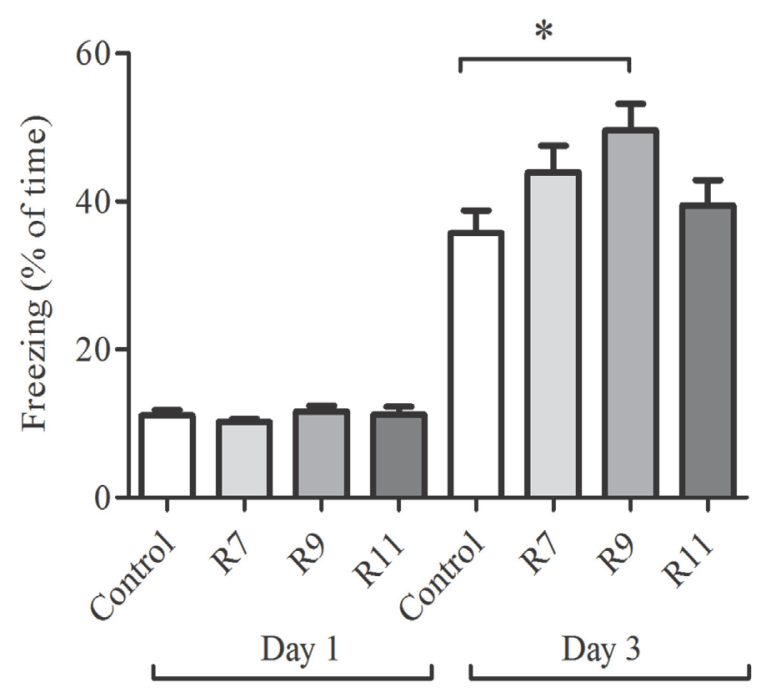

Figure 4. Contextual fear conditioning. Mean freezing levels $( \pm$ SEM) of controls $(n=10)$ and poly-arginine treated mice ( $\mathrm{n}=10$ each group). ANOVA followed by post-hoc Bonferroni test was used to determine if there were differences in freezing time between the control and experimental groups. There was a significant effect of the treatment upon freezing time as determined by one-way ANOVA $(F(3,36)=3.026$, p-value $=0.042)$. Bonferroni's Multiple Comparison Test revealed a significant difference $(\mathrm{p}<0.05)$ between the control and $\mathrm{R} 9$ treated groups.

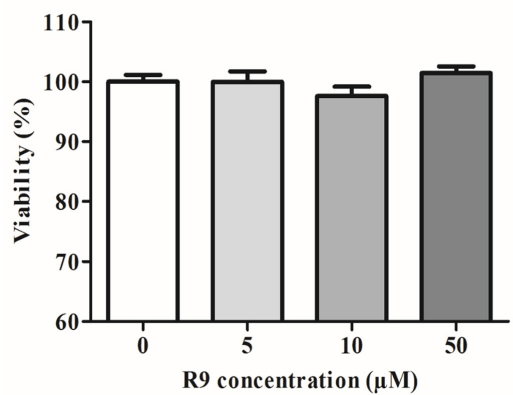

(a)

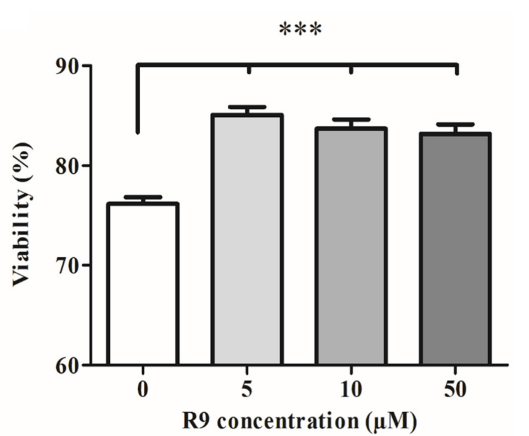

(b)

Figure 5. (a) Effects of R9 on the viability of PC12 cells. PC12 cells were exposed to various concentrations of R9 peptide $(0,5,10$, and $50 \mu \mathrm{M})$ for $48 \mathrm{~h}$, and then cell viability was assessed using MTT method. All results were not significantly different from the control values (presented as $100 \%$ viability), and there were no significant differences between the experimental groups with various poly-arginine concentrations. (b) Polyarginine R9 protects PC12 cells against oxidative injury. PC12 cells were cultured and preincubated with various concentrations of $\mathrm{R} 9$ peptide $(0,5,10$, and $50 \mu \mathrm{M})$ for $24 \mathrm{~h}$. Hydrogen peroxide $(400 \mu \mathrm{M})$ was used to induce oxidative damage. Viability was measured $24 \mathrm{~h}$ after hydrogen peroxide treatment. The viability of cells without hydrogen peroxide was designated as $100 \%$. The results are expressed as the means \pm SEM ( $n=48$ for each concentration). There were statistically significant differences between the control and experimental groups as determined by one-way ANOVA $(\mathrm{F}(3,188)=22.31, \mathrm{p}<0.0001)$. The differences between the treatment groups were not statistically significant. 


\subsection{Short-Term Treatment with Poly-Arginine R9 Peptide Has No Significant Effect upon the Rate of Intracellular Beta-Amyloidosis in 3xTg-AD Mice}

The $3 x \operatorname{Tg}$ mice exhibit both plaque and tangle pathology. $\mathrm{A} \beta$ deposition is characterized by intracellular progressive immunoreactivity in the hippocampus, frontal cortex, and amygdala as early as three to four months of age. Extracellular $\mathrm{A} \beta$ plaques appear by six-seven months [24]. To compare the rate of $\mathrm{A} \beta \mathrm{im}$ munoreactivity between the groups, we stained the brains with the specific $6 \mathrm{E} 10$ antibody. We observed extensive intracellular deposition in the hippocampi, amygdalae, and L4-L5 of the cortices (Figure 6). There were several extracellular plaques in the hippocampal areas. The quantitative analysis did not reveal significant differences in the levels of the 6E10 immunopositivity in the cortices, hili, and CA3 regions of the hippocampi between the control and experimental groups. However, we did note a non-significant decrease, by about $15 \%$, of the immunoreactivity rate in the treated with R9 poly-arginine group (Figure 6(e) and Figure 6(f)).
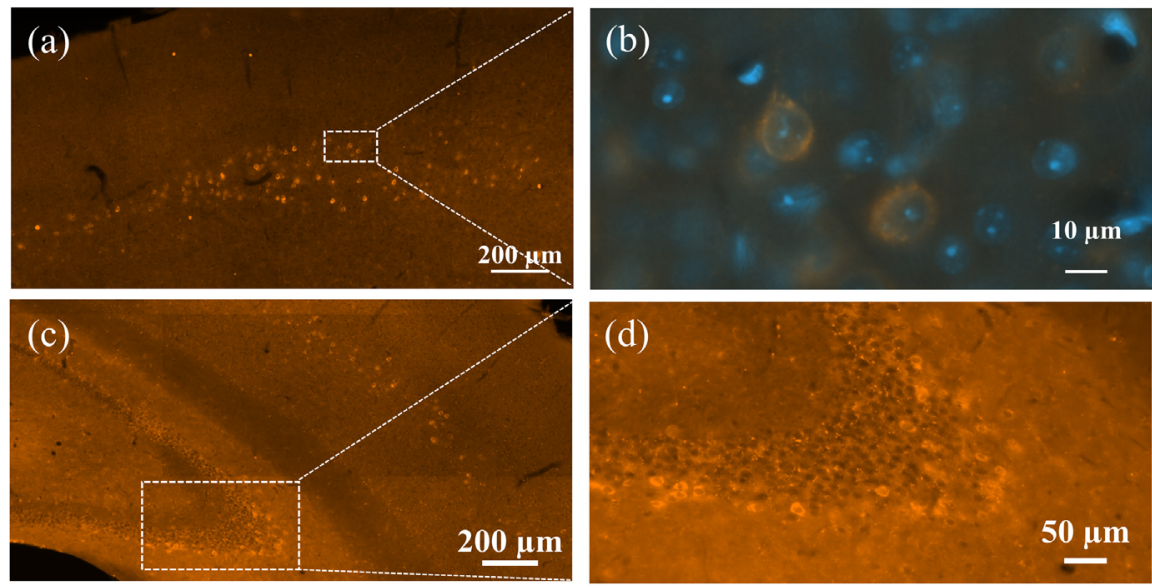

(e)

(f)
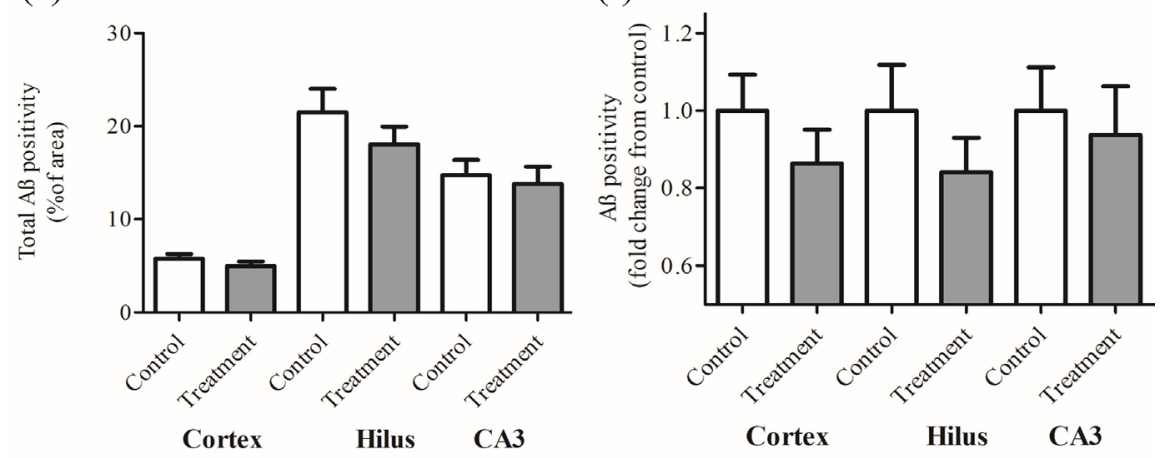

Figure 6. Cerebral $\mathrm{A} \beta$ deposits are visualized by $6 \mathrm{E} 10$ antibodies. Representative sections (20× magnification) of the cortex $(a, b)$ with intense deposition in layers III-IV, CA3 (c, d) area from R9 treated mice. The inset represents 100× magnification (double stained with DAPI and 6E10). Fluorescent intensities were evaluated within the area of $0.02 \mathrm{~mm}^{2}$ using Zen Blue 2.5 (Zeiss) with a manually set threshold, and average percentages of $\mathrm{A} \beta$-immunoreactivity in different brain areas are shown as bar graphs (e, $\mathrm{f}$ ) with means \pm SEM ( $n=25$ sections for each group of five animals). 


\subsection{Treatment with R9 Does Not Affect the Composition of Neurotoxic Oligomeric $\mathrm{A} \beta$}

Anti-oligomeric antibody (A11), which is specific to the oligomeric forms of $\mathrm{A} \beta$, was used to measure the levels of prefibrillar toxic species in hippocampal lysates. Quantification analysis of actin-normalized traces detected only a minor reduction by $2.34 \%$ in the level of $\mathrm{A} \beta$ oligomers (Figure S1).

\subsection{Poly-Arginine R9 Escalates the Expression Rate of Synapsin Ia}

Synapsin 1 isoform Ia is an associated with the cytoplasmic surface of synaptic vesicles neuronal phosphoprotein, which regulates synaptic transmission, in GABAergic synapses particularly, by controlling the synaptic vesicle dynamics at the presynaptic terminals [40]. Qin et al. demonstrated its relative regional deficit in the hippocampal formation of AD patients [41]. We observed a significant $34 \%$ increase of the levels of this protein in the hippocampi of the animals treated with poly-arginine R9 (Figure 7).

\subsection{Poly-Arginine R9 Treatment Induces Cellular Pathways Involved in Neuroplasticity and Oxidative Stress Protection}

Functional interpretation of the genes derived from the antibody microarray assay was performed using DAVID. There were 65 significantly up and down-regulated proteins with the change of expression more than $15 \%$ (Supplementary Table S1).

The microarray analysis (by DAVID Bioinformatics Resources web server with a preset threshold of $20 \%$ change) revealed that treatment of $3 \times \mathrm{Tg}$-AD mice with R9 poly-arginine led to positive regulation of several critical biological processes, including immune system process, nitrogen compound metabolic

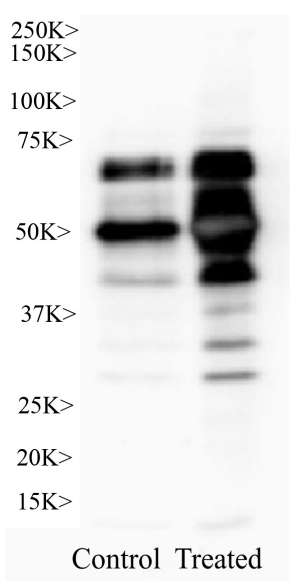

(a)

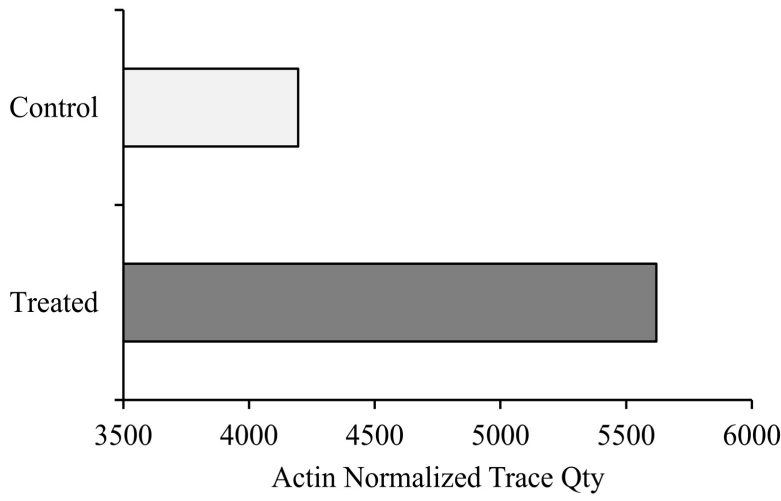

(b)

Figure 7. (a). Western blot analysis of Synapsin Ia (MW $\sim 67 \mathrm{kDa}$ ) with the NN171-2 antibody. (b) Bar chart showing the actin normalized trace quantities of Synapsin Ia immunopositivity in the control and experimental groups. Treatment with R9 led to a substantial increase by $34 \%$ of the expression levels of Synapsin Ia in the hippocampi of 3xTg mice. 
process, and biosynthetic process. Moreover, DAVID points out 30 other pathways with significant effect, which are involved in cell survival and neuroplasticity including response to oxygen-containing compounds, TNF signaling pathway, prolactin signaling pathway, and AKT Signaling Pathway (Figure 8(a)).

Response to the oxygen-containing compounds pathway seems very intriguing in the context of protection against $\mathrm{A} \beta$ induced cytotoxicity. We demonstrate that poly-arginine R9 is protective against oxidative injuryin cultured PC-12 cells. A bioinformatics approach provides us with information about 13 interrelated proteins with significantly up or downregulated expression levels that are involved in this vital biological process. The MAPK/ERK dual-specificity kinase 6 expression level was increased, by 32\%, in the experimental group. Also, superoxide dismutase [ $\mathrm{Cu}-\mathrm{Zn}$ ] levels were elevated by $41 \%$ in the brains of the treated animals. These enzymes play a critical role in cellular response to oxygen-containing compounds. It was convincingly demonstrated in a rat model, with NMDA excitotoxic lesion, that overexpression of superoxide dismutase [Cu-Zn] leads to neuroprotection and improved functional outcomes [42]. Our recent data acquired in the same model of $\mathrm{AD}$ treated with arginase inhibitor L-norvaline show that superoxide dismutase $[\mathrm{Cu}-\mathrm{Zn}]$ levels are elevated, by

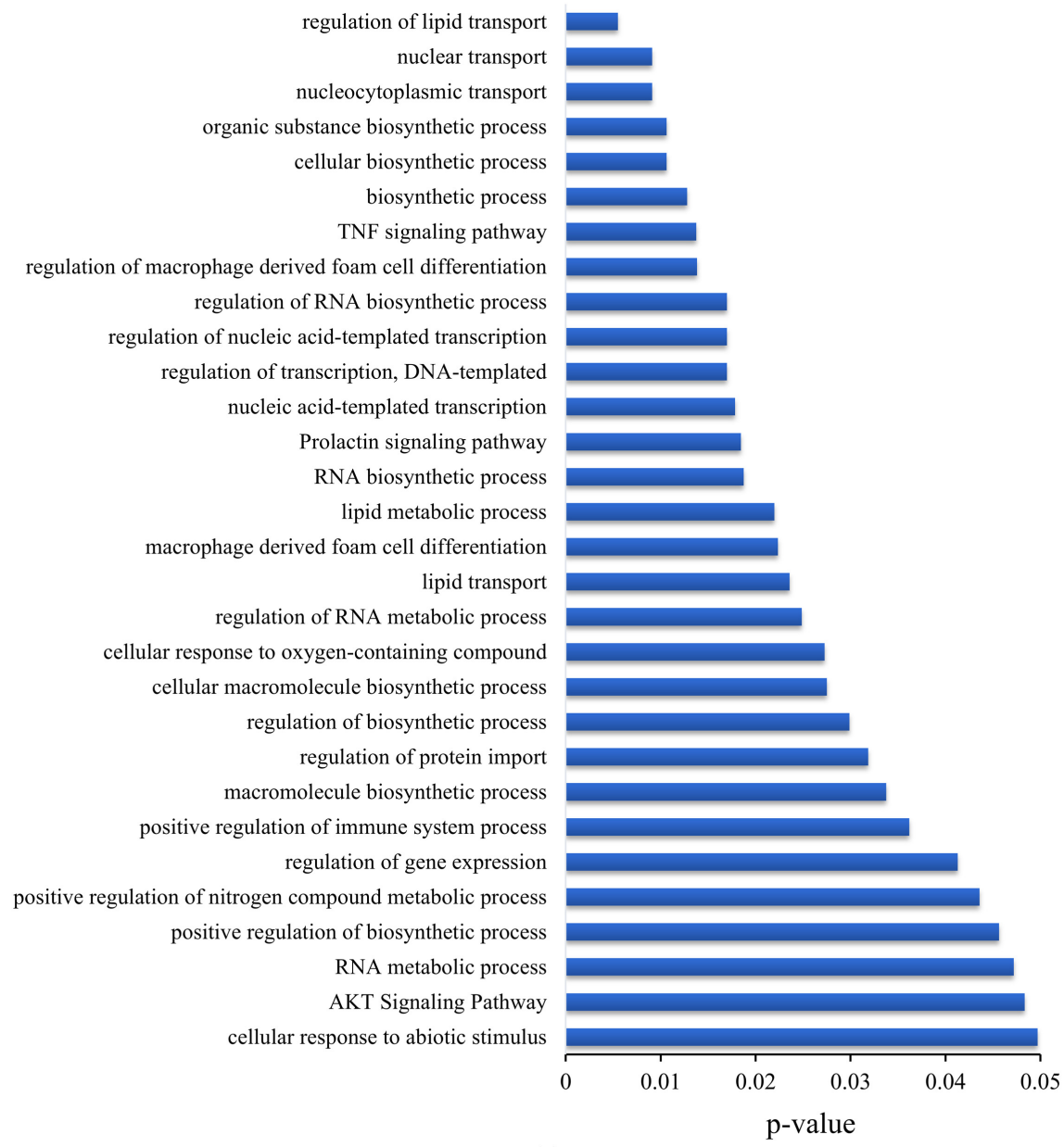

(a) 


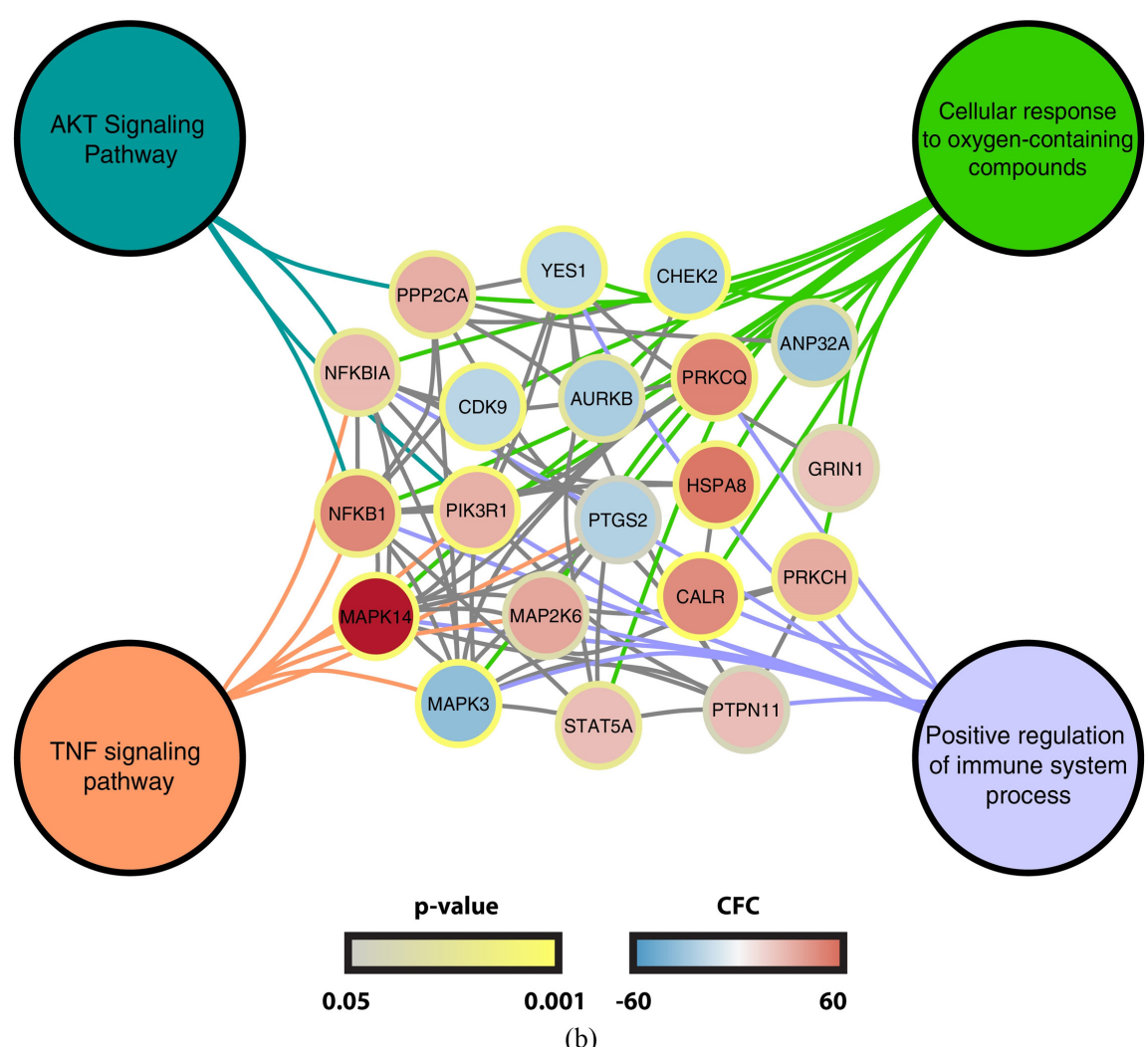

Figure 8. (a) A list of the biological pathways identified via David analysis (threshold is 20 percent of change). (b) Interactions between proteins identified as part of the induced by the treatment pathways graphed in Cytoscape (CFP-change from control \%). Highlighted enriched terms and associated differentially expressed proteins. Shown are differentially expressed proteins with at least $20 \%$ positive or negative CFC and p-value $<0.05$. STRING was used to build a physical and functional protein-protein association network in Cytoscape.

about $20 \%$, in the brains of the treated animals. L-norvaline improves the bioavailability of L-arginine via reduction of its utilization rate by arginase. Providing the animals with poly-arginine, we improve the bioavailability of arginine as well. Thus the mechanism might be the same.

Prostaglandin G/H synthase 2 is another enzyme, which shows a decrease in expression levels in $\mathrm{AD}$ brains [43], but exhibits elevation by $18 \%$ after the treatment with poly-arginine R9. Also, an inhibitor of NF-kappa-B alpha demonstrates an increase (by 25\%) in the experimental group. Sung S. et al. have shown that inhibition of NF-kappa-B significantly reduces the amyloid pathology in $\mathrm{AD}$ mice [44], so our treatment acts possibly via these mechanisms.

There are six proteins with significantly up/down-regulated levels of expression that represent the prolactin-signaling pathway. In general, prolactin possesses neuroprotective properties via activation of various cellular mechanisms and pathways [45]. We observed a significantly (with p-value equals 0.007 ) elevated, by $28 \%$, the expression rate of phosphatidylinositol 3-kinase regulatory subunit alpha. Yu et al. verified that this kinase plays a role in protection against 
$\mathrm{H}_{2} \mathrm{O}_{2}$-induced neuron degeneration [46]. Moreover, the levels of p44 MAP kinase decreased by $34 \%$. Murray et al. demonstrated that inhibition of this kinase protects hippocampal neurons in a cell-culture model of seizure activity [47].

To visualize molecular interaction networks and biological pathways, Cytoscape was applied (http://www.cytoscape.org). We built a functional map to link the differential changes in protein expression and the changes in network connectivity to biological pathways (Figure $8(\mathrm{~b})$ ).

Remarkably, seventeen regulatory proteins demonstrated very substantial and significant changes (ranging from 30 to 65 percent) of expression levels in poly-arginine treated animals compared to the vehicle-treated mice (Supplementary Table S1). Several significantly upregulated proteins are highly related to neuroplasticity, and $\mathrm{A} \beta$ protection were disclosed. For example, the expression level of calreticulin was amplified by $42 \%$ in the poly-arginine treated group. This multifunctional protein acts as a major $\mathrm{Ca}^{2+}$-binding protein in the lumen of the endoplasmic reticulum. Calreticulin interacts with APP by binding to the $\gamma$-cleavage site at the cell surface, influences the cleavage of the APP by $\gamma$-secretase and thus reduces $\mathrm{A} \beta$ production [48].

Moreover, several directly involved in synaptic transmission and plasticity proteins, which show significantly upregulated by the treatment levels of expression. Particularly, metabotropic glutamate receptor $\mathrm{V}$ levels were elevated by $29 \%$. Another glutamate receptor NMDA 1 showed a $21 \%$ increase, and NMDA 2A $16 \%$.

Additionally, the BDNF/NT-3 growth factors receptor, and nerve growth factor NGF receptor-tyrosine kinase, which facilitate synaptic plasticity, neuronal differentiation, avoidance of programmed cell death, demonstrate elevated by about $15 \%$ levels in the poly-arginine treated mice. Of note, these factors show a reduction in $\mathrm{AD}$ patients [49].

\section{Discussion}

The present study continues and extends the recent discoveries, specifying the neuroprotective properties of various poly-arginine peptides. Our results, for the first time, demonstrate a significant therapeutic effect of poly-arginine in vivo in a murine model of $\mathrm{AD}$. In particular, we report a significant improvement of memory acquisition following a four-week subcutaneous treatment with R9 peptide in 3xTg-AD mice. The effect was not pronounced in mice treated with R7 and R11.

In terms of the facilitation of neuroplasticity, we also demonstrate that poly-arginine peptides have the capacity to upgrade the hippocampal LTP in the presence of the aged $\mathrm{A} \beta(25$ - 35). Our comparative study utilizes R7, R9, and R11 peptides. We demonstrate, in ex vivo model of $\mathrm{AD}$, that poly-arginine $\mathrm{R} 9$ possesses unique neuroprotective properties. It rescues hippocampal LTP deteriorated by $\mathrm{A} \beta$ at a better rate than other tested agents do.

We test $\mathrm{R} 9$ in an in vitro model of cytotoxicity and show that the substance 
is not toxic. Additionally, we demonstrate that preincubation of PC12 cells with $5 \mu \mathrm{M}$ of $\mathrm{R} 9$ significantly mitigates peroxide-induced cytotoxicity.

Despite the lack of consensus regarding the precise molecular machinery mediating $\mathrm{A} \beta$-induced synaptic transmission impairment, there are several recent findings demonstrating the interference of $\mathrm{A} \beta$ oligomers with the vesicular transport at the presynaptic terminal [50]. Notably, there are strong data showing the involvement of Synapsin I in the A $\beta$-induced synaptic deficiency [51].

In general, synapsins are the key regulators of synaptic vesicle dynamics [40]. Synapsin I is a presynaptic protein, which regulates the rate of availability and readiness of synaptic vesicles to be released from the terminal of the GABAergic neurons especially [52]. Our WB results demonstrate that treatment with R9 peptide increases the expression levels of Synapsin Ia by $34 \%$ in the mice hippocampi. Of note, the data acquired via antibody array, which is much more sensitive, confirm the growth, however, show $21 \%$ increase in the expression levels for the same protein with a p-value of 0.005 . Therefore, we speculate that the drug facilitates synaptic plasticity via presynaptic mechanisms.

Additionally, antibody microarray analysis reveals that treatment with poly-arginine R9 leads to upregulation of several vital biological processes, including immune system process, nitrogen compound metabolic process, and biosynthetic process. Moreover, we disclose 30 other biological pathways, which are involved in cell survival and neuroplasticity, including response to oxygen-containing compounds, the TNF signaling pathway, prolactin-signaling pathway, and AKT signaling pathway.

Our assay provides information about eighteen regulatory proteins, which demonstrate ample changes (ranging from 30\% to 65\%) of expression levels in the poly-arginine treated group compared to the vehicle-treated mice. In particular, we emphasize the increase (by 43\%) in the expression level of calreticulin, which negatively regulates the cleavage of the APP by $\gamma$-secretase and thus reduces $\mathrm{A} \beta$ production [48]. Potentially, the observed amplification in the expression level of this $\mathrm{Ca}^{2+}$-binding protein could lead to a reduction of the $\mathrm{A} \beta$ oligomeric forms in the hippocampi of the treated animals. We have tried to confirm this via western blotting of the hippocampal lysates with the A11 antibody; however, detected only a minor $2.34 \%$ reduction.

According to current literature, in the course of the $\mathrm{AD}$ progression, the capacity of neurons to maintain the redox balance severely declines, which leads to the mitochondrial dysfunction, accumulation of free radicals, and neuronal injury [53]. Likewise, it was shown in transgenic mouse models of $\mathrm{AD}$ and in ex vivo experiments, using postmortem brain tissue taken from $\mathrm{AD}$ patients, that $\mathrm{A} \beta$ deposits are directly associated with free-radical generation [54].

In the context of the discussion about the role of free radicals in the pathogenesis of $\mathrm{AD}$, we point out a significant increase of the levels of superoxide dismutase $[\mathrm{Cu}-\mathrm{Zn}]$ in the experimental group. This enzyme plays a crucial role in cellular response to oxygen-containing compounds by catalyzing the dismuta- 
tion of the superoxide radical. It out-competes the detrimental effects of superoxide ion and protects the neurons from superoxide toxicity [55]. We show that the levels of this enzyme were elevated, by $41 \%$, in the hippocampi of the treated animals. Peluffo et al. demonstrated that overexpression of this enzyme leads to neuroprotection and improves functional outcome [42]. Our recent data acquired in the same model of $\mathrm{AD}$ treated with arginase inhibitor L-norvaline show that superoxide dismutase $[\mathrm{Cu}-\mathrm{Zn}]$ levels are elevated by about 20 percent in the brains of the treated animals [56]. L-norvaline improves the bioavailability of L-arginine via reduction of its utilization rate by arginase. Providing the animals with poly-arginine, we improved the bioavailability of arginine as well. Thus the mechanism might be the same. Therefore, we believe that the observed phenotype of the treated animals with poly-arginine might be partially explained by the elevation of superoxide dismutase expression levels.

Previous studies postulated that poly-arginine peptides are highly neuroprotective, and their efficacy is correlated with increasing arginine content [8]. Meloni et al. suggested that, for maximum neuroprotection in an ischemic stroke rodent model, approximately 15 arginine residues are required. In addition, Meloni et al. have demonstrated that polyarginine peptides and other arginine-rich peptides reduced intracellular neuronal calcium levels when administered before glutamic acid exposure [7] [8].

Further evidence provided by Ferrer-Montiel et al. supports the hypothesis that poly-arginine interferes with the calcium dynamics by targeting the cell surface ion channels and NMDA receptors, in particular [9]. Moreover, Marshal et al. demonstrated that poly-arginine $\mathrm{R} 7$ and its derivatives are capable of blocking NMDA-induced caspase activation, which, in turn, leads to a reduction of the rate of apoptosis [10]. Therefore, the ability of poly-arginine peptide to reduce toxic neuronal calcium influx is likely to mitigate downstream damaging effects of raised intracellular calcium such as caspase activation and mitochondrial and oxidative stress.

We verify that the treatment of $3 x \mathrm{Tg}$-AD mice with $\mathrm{R} 9$ poly-arginine peptide leads to a significant ( $\mathrm{p}$-value $=0.032$ ) reduction, by $15 \%$, of the levels of caspase- 6 in the animals' hippocampi. This enzyme plays a crucial role in neurodegenerative processes. It is responsible for the alternative non-secretase processing of APP and activated at early stages of AD [57] [58]. So, in the recent years, caspase- 6 was pointed out as a novel target in the treatment of $\mathrm{AD}$ [59].

MacDougall et al. have proven that poly-arginine R12 peptide application diminishes the expression of the glutamate receptor subunit NR2B upon neuronal cell surface [15]. Our results support the hypothesis that the effects of poly-arginine peptides are strongly connected to a delicate tuning of the neuronal excitation rate and intracellular calcium dynamics. The originally designed electrophysiological experiments establish that poly-arginine peptides are capable of inducing LTP impairment. Nevertheless, they partially rescue LTP reduced by A $\beta$. Additionally, antibody microarray analysis demonstrates that poly-arginine interferes 
with the rate of expression of various ion channels. It reduces the levels of voltage-dependent calcium channel gamma- 2 subunit by $12 \%$ and amplifies the expression levels of the glutamate ionotropic receptor NMDA (subunits epsilon-1 and zeta-1) by about $20 \%$. Another glutamate receptor-metabotropic glutamate receptor 5 (mGluR5) shows a very substantial by $30 \%$ elevation of its expression levels. Further research is needed to decipher the precise mechanism of their regulation by poly-arginine.

As an insight into the likely machinery underlying the neuroprotective effects of the poly-arginine peptides, we hypothesize that they serve as an additional source for L-arginine itself. Arginine deficiency is associated with the neurodegenerative progress of AD. Furthermore, its administration significantly decreases the frequency and severity of stroke-like symptoms [17], and its supplement in the diet of patients with senile dementia increases cognitive function [18].

There are several active trypsin-like proteases in the brain, which are capable of processing poly-arginine. For example, neuropsin has been well characterized and shown to hydrolyze the extracellular matrix components and regulate learning and memory in the healthy brain [60]. Therefore, we believe, that poly-arginine provides the brain with an additional amount of the amino acid, which might be vital because of the limited capacity of its transporter.

To conclude we accentuate that positively charged poly-arginine rich compounds are capable of interaction with various negatively charged bioactive molecules. For example, they bind to extremely negative proteoglycans, which play a role in the development of $\mathrm{AD}$ [61]. Snow et al. demonstrated the presence of heparan sulfate proteoglycans in neuritic plaques [62]. Therefore it was suggested that inhibition of the interaction between amyloid and proteoglycans could prevent $\mathrm{AD}$ development [63]. We propose that interference with the $\mathrm{A} \beta$-proteoglycans interaction could be a likely mechanism of R9 mediated modulation of the $\mathrm{AD}$ pathogenesis.

\section{Conclusion}

Despite some limitations of our study, the present research advances knowledge of the neuroprotective properties of various poly-arginine containing compounds with an emphasis upon the neurodegenerative diseases and $\mathrm{AD}$, particularly. We state that poly-arginine peptides represent a promising cluster of neuroprotective molecules, possessing multiple potential biological qualities, which might be tailored for the treatment of a range of neurodegenerative disorders. Additional research is required to be performed to discover an optimal concentration of the substance, which provides the best neuroprotection. Likewise, other AD models can be utilized to validate the results, elucidate and confirm the precise neuroprotective mechanisms.

\section{Acknowledgements}

This research was supported by a Marie Curie CIG grant 322113, a Leir Founda- 
tion grant, a Ginzburg family foundation grant, and a Katz foundation grant to AOS. Electrophysiological experiments were supported by Russian Science Foundation (RSF; grant No. 14-25-00072). We gratefully acknowledge Mr. Basem Hijazi for his valuable advice in the statistical analysis.

\section{Conflicts of Interest}

The authors declare no conflicts of interest regarding the publication of this paper.

\section{References}

[1] Prince, M., Comas-Herrera, A., Knapp, M., Guerchet, M. and Karagiannidou, M. (2016) World Alzheimer Report 2016 Improving Healthcare for People Living with Dementia. Coverage, Quality and Costs Now and in the Future. Alzheimer's Disease International, 1-140. https://www.alz.co.uk/research/world-report-2016

[2] Prince, M., Bryce, R., Albanese, E., Wimo, A., Ribeiro, W. and Ferri, C.P. (2013) The Global Prevalence of Dementia: A Systematic Review and Metaanalysis. Alzheimer's \& Dementia, 9, 63-75. https://doi.org/10.1016/j.jalz.2012.11.007

[3] Prince, M., Wimo, A., Guerchat, M., Ali, G.-C., Wu, Y.-T. and Prina, M. (2015) World Alzheimer Report 2015. Alzheimer's Disease International, 1-84.

[4] Torre, L. and Rebecca Siegel, A.J. (2015) Global Cancer Facts \& Figures. 3rd Edition, American Cancer Society, 1-64.

[5] Pajouhesh, H. and Lenz, G.R. (2005) Medicinal Chemical Properties of Successful Central Nervous System Drugs. NeuroRx, 2, 541-553.

https://doi.org/10.1602/neurorx.2.4.541

[6] Gotanda, Y., Wei, F.Y., Harada, H., Ohta, K., Nakamura, K.I. and Tomizawa, K. (2014) Ushijima, Efficient transduction of 11 Poly-Arginine Peptide in an Ischemic Lesion of Mouse Brain. Journal of Stroke and Cerebrovascular Diseases, 23, 2023-2030. https://doi.org/10.1016/j.jstrokecerebrovasdis.2014.02.027

[7] Meloni, B.P., Milani, D., Cross, J.L., Clark, V.W., Edwards, A.B., Anderton, R.S., Blacker, D.J. and Knuckey, N.W. (2017) Assessment of the Neuroprotective Effects of Arginine-Rich Protamine Peptides, Poly-Arginine Peptides (R12-Cyclic, R22) and Arginine-Tryptophan-Containing Peptides Following in Vitro Excitotoxicity and/or Permanent Middle Cerebral Artery Occlusion in Rats. NeuroMolecular Medicine, 9, 271-285. https://doi.org/10.1007/s12017-017-8441-2

[8] Meloni, B.P., Brookes, L.M., Clark, V.W., Cross, J.L., Edwards, A.B., Anderton, R.S., Hopkins, R.M., Hoffmann, K. and Knuckey, N.W. (2015) Poly-Arginine and Arginine-Rich Peptides Are Neuroprotective in Stroke Models. Journal of Cerebral Blood Flow \& Metabolism, 35, 993-1004. https://doi.org/10.1038/jcbfm.2015.11

[9] Ferrer-Montiel, A.V., Merino, J.M., Blondelle, S.E., Perez-Payà, E., Houghten, R.A. and Montal, M. (1998) Selected Peptides Targeted to the NMDA Receptor Channel Protect Neurons from Excitotoxic Death. Nature Biotechnology, 16, 286-291. https://doi.org/10.1038/nbt0398-286

[10] Marshall, J., Wong, K.Y., Rupasinghe, C.N., Tiwari, R., Zhao, X., Berberoglu, E.D., Sinkler, C., Liu, J., Lee, I., Parang, K., Spaller, M.R., Hüttemann, M. and Goebel, D.J. (2015) Inhibition of N-Methyl-D-Aspartate-Induced Retinal Neuronal Death by Polyarginine Peptides Is Linked to the Attenuation of Stress-Induced Hyperpolarization of the Inner Mitochondrial Membrane Potential. The Journal of Biological 
Chemistry, 290, 22030-22048. https://doi.org/10.1074/jbc.M115.662791

[11] Kadenbach, B., Arnold, S., Lee, I. and Hüttemann, M. (2004) The Possible Role of Cytochrome C Oxidase in Stress-Induced Apoptosis and Degenerative Diseases. Biochimica et Biophysica Acta (BBA)-Bioenergetics, 1655, 400-408. https://doi.org/10.1016/j.bbabio.2003.06.005

[12] Cabezas-Opazo, F.A., Vergara-Pulgar, K., Pérez, M.J., Jara, C., Osorio-Fuentealba, C. and Quintanilla, R.A. (2015) Mitochondrial Dysfunction Contributes to the Pathogenesis of Alzheimer's Disease. Oxidative Medicine and Cellular Longevity, 2015, Article ID: 509654. https://doi.org/10.1155/2015/509654

[13] Moreira, P.I., Carvalho, C., Zhu, X., Smith, M.A. and Perry, G. (2010) Mitochondrial Dysfunction Is a Trigger of Alzheimer's Disease Pathophysiology. Biochimica et Biophysica Acta (BBA)-Molecular Basis of Disease, 1802, 2-10. https://doi.org/10.1016/j.bbadis.2009.10.006

[14] Cook, D.R., Gleichman, A.J., Cross, S.A., Doshi, S., Ho, W., Jordan-Sciutto, K.L., Lynch, D.R. and Kolson, D.L. (2011) NMDA Receptor Modulation by the Neuropeptide Apelin: Implications for Excitotoxic Injury. Journal of Neurochemistry, 118, 1113-1123. https://doi.org/10.1111/j.1471-4159.2011.07383.x

[15] MacDougall, G., Anderton, R.S., Edwards, A.B., Knuckey, N.W. and Meloni, B.P. (2017) The Neuroprotective Peptide Poly-Arginine-12 (R12) Reduces Cell Surface Levels of NMDA NR2B Receptor Subunit in Cortical Neurons; Investigation into the Involvement of Endocytic Mechanisms. Journal of Molecular Neuroscience, 61, 235-246. https://doi.org/10.1007/s12031-016-0861-1

[16] Ibanez, C., et al. (2012) Toward a Predictive Model of Alzheimer's Disease Progression Using Capillary Electrophoresis-Mass Spectrometry Metabolomics. Analytical Chemistry, 84, 8532-8540. https://doi.org/10.1021/ac301243k

[17] Koga, Y., Akita, Y., Nishioka, J., Yatsuga, S., Povalko, N., Tanabe, Y., Fujimoto, S. and Matsuishi, T. (2005) L-Arginine Improves the Symptoms of Strokelike Episodes in MELAS. Neurology, 64, 710-712. https://doi.org/10.1212/01.WNL.0000151976.60624.01

[18] Ohtsuka, Y. and Nakaya, J. (2000) Effect of Oral Administration of L-Arginine on Senile Dementia. The American Journal of Medicine, 108, 439. https://doi.org/10.1016/S0002-9343(99)00396-4

[19] O’Kane, R.L., Viña, J.R., Simpson, I., Zaragozá, R., Mokashi, A. and Hawkins, R.A (2006) Cationic Amino Acid Transport across the Blood-Brain Barrier Is Mediated Exclusively by System $\mathrm{y}^{+}$. American Journal of Physiology-Endocrinology and Metabolism, 291, E412-E419. https://doi.org/10.1152/ajpendo.00007.2006

[20] Stoll, J., Wadhwani, K.C. and Smith, Q.R. (1993) Identification of the Cationic Amino Acid Transporter (System $\mathrm{y}^{+}$) of the Rat Blood-Brain Barrier. Journal of Neurochemistry, 60, 1956-1959. https://doi.org/10.1111/j.1471-4159.1993.tb13428.x

[21] Tachikawa, M. and Hosoya, K.-I. (2011) Transport Characteristics of Guanidino Compounds at the Blood-Brain Barrier and Blood-Cerebrospinal Fluid Barrier: Relevance to Neural Disorders. Fluids and Barriers of the CNS, 8, 13. https://doi.org/10.1186/2045-8118-8-13

[22] Polis, B. and Samson, A.O. (2018) Arginase as a Potential Target in the Treatment of Alzheimer's Disease. Advances in Alzheimer's Disease, 7, 119-140. https://doi.org/10.4236/aad.2018.74009

[23] Fonar, G., Polis, B., Meirson, T., Maltsev, A. and Samson, A.O. (2018) Intracerebroventricular Administration of L-Arginine Improves Spatial Memory Acquisition in Triple Transgenic Mice via Reduction of Oxidative Stress and Apoptosis. Journal 
of Neuroscience, 9, 43-53.

[24] Oddo, S., Caccamo, A., Shepherd, J.D., Murphy, M.P., Golde, T.E., Kayed, R., Metherate, R., Mattson, M.P., Akbari, Y. and LaFerla, F.M. (2003) Triple-Transgenic model of Alzheimer's Disease with Plaques and Tangles: Intracellular A $\beta$ and Synaptic Dysfunction. Neuron, 39, 409-421. https://doi.org/10.1016/S0896-6273(03)00434-3

[25] Milani, D., Knuckey, N.W., Anderton, R.S., Cross, J.L. and Meloni, B.P. (2016) The R18 Polyarginine Peptide Is More Effective than the TAT-NR2B9c (NA-1) Peptide When Administered 60 Minutes after Permanent Middle Cerebral Artery Occlusion in the Rat. Stroke Research and Treatment, 2016, Article ID: 2372710.

[26] Milani, D., Bakeberg, M., Cross, J., Clark, V., Anderton, S., Blacker, D.J., Knuckey, N.W. and Meloni, B.P. (2018) Comparison of Neuroprotective Efficacy of Poly-Arginine R18 and R18D (D-Enantiomer) Peptides Following Permanent Middle Cerebral Artery Occlusion in the Wistar Rat and in Vitro Toxicity Studies. PLoS ONE, 13, e0193884. https://doi.org/10.1371/journal.pone.0193884

[27] Wehner, J.M. and Radcliffe, R.A. (2004) Cued and Contextual Fear Conditioning in Mice. Current Protocols in Neuroscience, 27, 8.5C.1-8.5C.14.

https://doi.org/10.1002/0471142301.ns0805cs27

[28] Anagnostaras, S.G., Gale, G.D. and Fanselow, M.S. (2001) Hippocampus and Contextual Fear Conditioning: Recent Controversies and Advances. Hippocampus, 11, 8-17. https://doi.org/10.1002/1098-1063(2001)11:1<8::AID-HIPO1015>3.0.CO;2-7

[29] Gellért, L. and Varga, D.P. (2016) Locomotion Activity Measurement in an Open Field for Mice. Bio-Protocol, 6, 2-6. https://doi.org/10.21769/BioProtoc.1857

[30] Jung, J.Y., Roh, K.H., Jeong, Y.J., Kim, S.H., Lee, E.J., Kim, M.S., Oh, W.M., Oh, H.K. and Kim, W.J. (2008) Estradiol Protects PC12 Cells against $\mathrm{CoCl}_{2}$-Induced Apoptosis. Brain Research Bulletin, 76, 579-585. https://doi.org/10.1016/j.brainresbull.2008.04.006

[31] Scotter, E.L., Goodfellow, C.E., Graham, E.S., Dragunow, M. and Glass, M. (2010) Neuroprotective Potential of $\mathrm{CB}_{1}$ Receptor Agonists in an in Vitro Model of Huntington's Disease. British Journal of Pharmacology, 160, 747-761. https://doi.org/10.1111/j.1476-5381.2010.00773.x

[32] Wan, J., Fu, A.K.Y., Ip, F.C.F., Ng, H.K., Hugon, J., Page, G., Wang, J.H., Lai, K.O., Wu, Z. and Ip, N.Y. (2010) Tyk2/STAT3 Signaling Mediates $\beta$-Amyloid-Induced Neuronal Cell Death: Implications in Alzheimer's Disease. The Journal of Neuroscience, 30, 6873-6881. https://doi.org/10.1523/JNEUROSCI.0519-10.2010

[33] Yao, Z., Drieu, K. and Papadopoulos, V. (2001) The Ginkgo biloba Extract EGb 761 Rescues the PC12 Neuronal Cells from $\beta$-Amyloid-Induced Cell Death by Inhibiting the Formation of $\beta$-Amyloid-Derived Diffusible Neurotoxic Ligands. Brain Research, 889, 181-190. https://doi.org/10.1016/S0006-8993(00)03131-0

[34] Heo, H.J. and Lee, C.Y. (2005) Strawberry and Its Anthocyanins Reduce Oxidative Stress-Induced Apoptosis in PC12 Cells. Journal of Agricultural and Food Chemistry, 53, 1984-1989. https://doi.org/10.1021/jf0486161

[35] Gage, G.J., Kipke, D.R. and Shain, W. (2012) Whole Animal Perfusion Fixation for Rodents. Journal of Visualized Experiments, 65, e3564. https://doi.org/10.3791/3564

[36] Kayed, R., Head, E., Thompson, J.L., McIntire, T.M., Milton, S.C., Cotman, C.W. and Glabel, C.G. (2003) Common Structure of Soluble Amyloid Oligomers Implies Common Mechanism of Pathogenesis. Science, 300, 486-489.

https://doi.org/10.1126/science.1079469 
[37] Huttner, W.B., Schiebler, W., Greengard, P. and De Camilli, P. (1983) Synapsin I (Protein I), a Nerve Terminal-Specific Phosphoprotein. III. Its Association with Synaptic Vesicles Studied in a Highly Purified Synaptic Vesicle Preparation. Journal of Cell Biology, 96, 1374-1388. https://doi.org/10.1083/jcb.96.5.1374

[38] Sarvey, J.M., Burgard, E.C. and Decker, G. (1989) Long-Term Potentiation: Studies in the Hippocampal Slice. Journal of Neuroscience Methods, 28, 109-124. https://doi.org/10.1016/0165-0270(89)90016-2

[39] Holscher, C., Gengler, S., Gault, V.A., Harriott, P. and Mallot, H.A. (2007) Soluble Beta-Amyloid[25-35] Reversibly Impairs Hippocampal Synaptic Plasticity and Spatial Learning. European Journal of Pharmacology, 561, 85-90. https://doi.org/10.1016/j.ejphar.2007.01.040

[40] Song, S.-H. and Augustine, G.J. (2015) Synapsin Isoforms and Synaptic Vesicle Trafficking. Molecules and Cells, 38, 936-940. https://doi.org/10.14348/molcells.2015.0233

[41] Qin, S., Hu, X.Y., Xu, H. and Zhou, J.N. (2004) Regional Alteration of Synapsin I in the Hippocampal Formation of Alzheimer's Disease Patients. Acta Neuropathologica, 107, 209-215. https://doi.org/10.1007/s00401-003-0800-4

[42] Peluffo, H., Acarin, L., Arís, A., González, P., Villaverde, A., Castellano, B. and González, B. (2006) Neuroprotection from NMDA Excitotoxic Lesion by $\mathrm{Cu} / \mathrm{Zn}$ Superoxide Dismutase Gene Delivery to the Postnatal Rat Brain by a Modular Protein Vector. BMC Neuroscience, 7, 35. https://doi.org/10.1186/1471-2202-7-35

[43] Chang, J.W., Coleman, P.D. and O’Banion, M.K. (1996) Prostaglandin G/H synthase-2 (Cyclooxygenase-2) mRNA Expression is Decreased in Alzheimer's Disease. Neurobiology of Aging, 17, 801-808. https://doi.org/10.1016/0197-4580(96)00110-8

[44] Sung, S., Yang, H., Uryu, K., Lee, E.B., Zhao, L., Shineman, D., Trojanowski, J.Q., Lee, V.M. and Pratico, D. (2004) Modulation of Nuclear Factor- $\kappa$ B Activity by Indomethacin Influences $\mathrm{A} \beta$ Levels but Not $\mathrm{A} \beta$ Precursor Protein Metabolism in a Model of Alzheimer's Disease. The American Journal of Pathology, 165, 2197-2206. https://doi.org/10.1016/S0002-9440(10)63269-5

[45] Torner, L. (2016) Actions of Prolactin in the Brain: From Physiological Adaptations to Stress and Neurogenesis to Psychopathology. Frontiers in Endocrinology, 7, 25. https://doi.org/10.3389/fendo.2016.00025

[46] Yu, X., Rajala, R.V.S., McGinnis, J.F., Li, F., Anderson, R.E., Yan, X., Li, S., Elias, R.V., Knapp, R.R., Zhou, X. and Cao, W. (2004) Involvement of Insulin/Phosphoinositide 3-Kinase/Akt Signal Pathway in 17 $\beta$-Estradiol-Mediated Neuroprotection. The Journal of Biological Chemistry, 279, 13086-13094. https://doi.org/10.1074/jbc.M313283200

[47] Murray, B., Alessandrini, A., Cole, A.J., Yee, A.G. and Furshpan, E.J. (1998) Inhibition of the P44/42 MAP Kinase Pathway Protects Hippocampal Neurons in a Cell-Culture Model of Seizure Activity. Proceedings of the National Academy of Sciences of the United States of America, 95, 11975-11980. https://doi.org/10.1073/pnas.95.20.11975

[48] Stemmer, N., Strekalova, E., Djogo, N., Plöger, F., Loers, G., Lutz, D., Buck, F., Michalak, M., Schachner, M. and Kleene, R. (2013) Generation of Amyloid- $\beta$ Is Reduced by the Interaction of Calreticulin with Amyloid Precursor Protein, Presenilin and Nicastrin. PLOS ONE, 8, e61299. https://doi.org/10.1371/journal.pone.0061299

[49] Budni, J., Bellettini-Santos, T., Mina, F., Lima Garcez, M. and Ioppi Zugno, A. (2015) The Involvement of BDNF, NGF and GDNF in Aging and Alzheimer's Dis- 
ease. Aging and Disease, 6, 331. https://doi.org/10.14336/AD.2015.0825

[50] Nimmrich, V. and Ebert, U. (2009) Is Alzheimer's Disease a Result of Presynaptic Failure? Synaptic Dysfunctions Induced by Oligomeric Beta-Amyloid. Reviews in the Neurosciences, 20, 1-12. https://doi.org/10.1515/REVNEURO.2009.20.1.1

[51] Marsh, J., Bagol, S.H., Williams, R.S.B., Dickson, G. and Alifragis, P. (2017) Synapsin I Phosphorylation Is Dysregulated by Beta-Amyloid Oligomers and Restored by Valproic Acid. Neurobiology of Disease, 106, 63-75. https://doi.org/10.1016/j.nbd.2017.06.011

[52] Song, S.-H. and Augustine, G.J. (2016) Synapsin Isoforms Regulating GABA Release from Hippocampal Interneurons. Journal of Neuroscience, 36, 6742-6757. https://doi.org/10.1523/JNEUROSCI.0011-16.2016

[53] Chen, X., Guo, C. and Kong, J. (2012) Oxidative Stress in Neurodegenerative Diseases. Neural Regeneration Research, 7, 376-385.

[54] Mclellan, M.E., Kajdasz, S.T., Hyman, B.T. and Bacskai, B.J. (2003) In Vivo Imaging of Reactive Oxygen Species Specifically Associated with Thioflavine S-Positive Amyloid Plaques by Multiphoton Microscopy. Journal of Neuroscience, 23, 2212-2217. https://doi.org/10.1523/JNEUROSCI.23-06-02212.2003

[55] Tainer, J.A., Getzoff, E.D., Richardson, J.S. and Richardson, D.C. (1983) Structure and Mechanism of Copper, Zinc Superoxide Dismutase. Nature, 306, 284-287. https://doi.org/10.1038/306284a0

[56] Polis, B., Elliott, E., Henn, H. and Samson, A.O. (2018) L-Norvaline Reverses Cognitive Decline and Synaptic Loss in a Murine Model of Alzheimer's Disease. Neurotherapeutics, 15, 1036-1054. https://doi.org/10.1007/s13311-018-0669-5

[57] Pellegrini, L., Passer, B.J., Tabaton, M., Ganjei, J.K. and D’Adamio, L. (1999) Alternative, Non-Secretase Processing of Alzheimer's $\beta$-Amyloid Precursor Protein during Apoptosis by Caspase-6 and -8. The Journal of Biological Chemistry, 274, 21011-21016. https://doi.org/10.1074/jbc.274.30.21011

[58] Klaiman, G., Petzke, T.L., Hammond, J. and LeBlanc, A.C. (2008) Targets of Caspase-6 Activity in Human Neurons and Alzheimer Disease. Molecular \& Cellular Proteomics, 7, 1541-1555. https://doi.org/10.1074/mcp.M800007-MCP200

[59] Leblanc, A.C. (2013) Caspase-6 as a Novel Early Target in the Treatment of Alzheimer's Disease. European Journal of Neuroscience, 37, 2005-2018. https://doi.org/10.1111/ejn.12250

[60] Wang, Y., Luo, W. and Reiser, G. (2008) Trypsin and Trypsin-Like Proteases in the Brain: Proteolysis and Cellular Functions. Cellular and Molecular Life Sciences, 65, 237-252. https://doi.org/10.1007/s00018-007-7288-3

[61] Bishop, J.R., Schuksz, M. and Esko, J.D. (2007) Heparan Sulphate Proteoglycans Fine-Tune Mammalian Physiology. Nature, 446, 1030-1037. https://doi.org/10.1038/nature05817

[62] Snow, A.D., Willmer, J. and Kisilevsky, R. (1987) Sulfated Glycosaminoglycans: A Common Constituent of All Amyloids? Laboratory Investigation, 56, 120-123.

[63] Van Horssen, J., Wesseling, P., Van Den Heuvel, L.P., De Waal, R.M. and Verbeek, M.M. (2003) Heparan Sulphate Proteoglycans in Alzheimer's Disease and Amyloid-Related Disorders. The Lancet Neurology, 2, 482-492. https://doi.org/10.1016/S1474-4422(03)00484-8 


\section{Supplementary}

Table S1. Globally Normalized Values for the signal intensity of samples analyzed with the KAM-1150E antibody microarray data. A list of proteins, which demonstrated significant ( $p$-value $<0.05)$ changes $(\leq$ or $\geq 15 \%$ ) of expression levels in poly-arginine treated animals compared to the vehicle-treated mice. CFC stands for change from control \% (Treated vs. Control). Last column presents Student $\mathrm{T}$ test $\mathrm{p}$ values.

\begin{tabular}{|c|c|c|c|c|}
\hline$\#$ & Target Name with Alias & Full Target Protein Name & $\% \mathrm{CFC}$ & $\mathrm{p}$ value \\
\hline 1 & p38a MAPK (MAPK14; CSBP; MXI2; SAPK2a) & Mitogen-activated protein-serine kinase p38 alpha & 65.44 & 0.007 \\
\hline 2 & EPM2A (LAFPTPase) & Laforin & 57.01 & 0.044 \\
\hline 3 & Hsc70 (HSPA8; Hsc70; HSP73; HSPA10) & Heat shock cognate $71 \mathrm{kDa}$ protein & 50.76 & 0.011 \\
\hline 4 & PKCq (PRKCQ; PKC-theta) & Protein-serine kinase $\mathrm{C}$ theta & 46.24 & 0.013 \\
\hline 5 & NFkappaB p50 & NF-kappa-B p50 nuclear transcription factor & 44.90 & 0.015 \\
\hline 6 & REEP2 (SGC32445) & Receptor expression-enhancing protein 2 & 42.89 & 0.024 \\
\hline 7 & Calreticulin (CALR; calregulin; grp60; HACBP) & Calreticulin & 42.81 & 0.002 \\
\hline 8 & SOD1 (hSod1) & Superoxide dismutase $[\mathrm{Cu}-\mathrm{Zn}]$ & 41.05 & 0.004 \\
\hline 9 & LGI1 (Epitempin-1) & Leucine-rich glioma-inactivated protein 1 & 36.63 & 0.010 \\
\hline 10 & PANX2 & Pannexin-2 & 32.00 & 0.003 \\
\hline 11 & MKK6 (MAP2K6; MEK6) & MAPK/ERK dual-specificity kinase 6 & 31.71 & 0.035 \\
\hline 12 & AHSA1 (AHA1) & Activator of $90 \mathrm{kDa}$ heat shock protein ATPase homolog 1 & 30.61 & 0.008 \\
\hline 13 & $\mathrm{PKCh}(\mathrm{PRKCH})$ & Protein kinase $\mathrm{C}$ eta type & 30.27 & 0.012 \\
\hline 14 & $\mathrm{CDC} 25 \mathrm{C}$ & Dual specificity protein phosphatase $25 \mathrm{C}$ & 29.78 & 0.015 \\
\hline 15 & mGluR5 (GRM5; GPRC1E; MGLUR5) & Metabotropic glutamate receptor 5 & 29.12 & 0.006 \\
\hline 16 & $\mathrm{PP} 2 \mathrm{~A} / \mathrm{Ca}(\mathrm{PPP} 2 \mathrm{CA}) /{ }^{\prime} \mathrm{PP} 2 \mathrm{~A} / \mathrm{Cb}(\mathrm{PPP} 2 \mathrm{CB})$ & $\begin{array}{l}\text { Protein-serine phosphatase } 2 \mathrm{~A} \text {-catalytic } \\
\text { subunit-alpha and beta isoform }\end{array}$ & 28.89 & 0.019 \\
\hline 17 & PIK3R1 (PI3K p85) & Phosphatidylinositol 3-kinase regulatory subunit alpha & 27.76 & 0.007 \\
\hline 18 & Mnk2 (MKNK2) & MAP kinase-interacting serine-threonine kinase 2 & 27.47 & 0.015 \\
\hline 19 & HSP40 (DNAJB1; DNAJ1; HDJ1; HSPF1) & DnaJ homolog subfamily B member 1 & 26.60 & 0.039 \\
\hline 20 & $\mathrm{IkBa}$ & Inhibitor of NF-kappa-B alpha (MAD3) & 24.56 & 0.022 \\
\hline 21 & PTP1D (PTPN11; PTP2C; SHP2; SHPTP2; Syp) & Protein-tyrosine phosphatase, receptor $1 \mathrm{D}$ & 22.95 & 0.041 \\
\hline 22 & STAT5A & Signal transducer and activator of transcription $5 \mathrm{~A}$ & 22.73 & 0.022 \\
\hline 23 & Synapsin 1 & Synapsin 1 isoform Ia & 20.89 & 0.005 \\
\hline 24 & GRIN1 (NMDAR1) & Glutamate receptor ionotropic, NMDA 1 & 20.63 & 0.036 \\
\hline 25 & SGK3 & Serum/glucocorticoid regulated kinase 3 & 19.49 & 0.038 \\
\hline 26 & NPM1 (B23) & Nucleophosmin & 18.97 & 0.006 \\
\hline 27 & mTOR (FRAP) & Mammalian target of rapamycin & 18.90 & 0.011 \\
\hline 28 & Raf1 (c-Raf) & Raf1 proto-oncogene-encoded protein-serine kinase & 18.26 & 0.026 \\
\hline 29 & KHS1 (MAP4K5; KHS) & Kinase homologous to SPS1/STE20 & 17.98 & 0.038 \\
\hline 30 & ATAD1 ATPase & ATPase family AAA domain-containing protein 1 & 17.81 & 0.039 \\
\hline 31 & Mat1 (MNAT1) & CDK-activating kinase assembly factor MAT1 & 17.81 & 0.039 \\
\hline 32 & $\operatorname{COX} 2$ & Prostaglandin G/H synthase 2 & 17.59 & 0.020 \\
\hline
\end{tabular}




\section{Continued}

\begin{tabular}{|c|c|c|c|c|}
\hline 33 & LIMK1 & LIM domain kinase 1 & 16.94 & 0.015 \\
\hline 34 & PGR (PR) & Progesterone receptor & 16.79 & 0.001 \\
\hline 35 & Grp170 (HYOU1; ORP-150) & Hypoxia up-regulated protein 1 & 16.17 & 0.003 \\
\hline 36 & NMDAR2A NMDA & Glutamate receptor ionotropic, NMDA 2A & 16.11 & 0.030 \\
\hline 37 & APG1 & $\begin{array}{l}\text { Hsp 70-related heat shock protein } 1 \\
\text { (osmotic stress protein } 94 \text { (OSP94)) }\end{array}$ & 15.78 & 0.019 \\
\hline 38 & TrkB (NTRK2) & BDNF/NT-3 growth factors receptor & 15.61 & 0.030 \\
\hline 39 & PCDH-gamma-A3 (PCDHGA3) & Protocadherin gamma-A3 & 15.49 & 0.021 \\
\hline 40 & TrkA (NGFR; NTRK1) & Nerve growth factor (NGF) receptor-tyrosine kinase & 15.19 & 0.002 \\
\hline 41 & CASP6 & Caspase-6 & -15.0 & 0.032 \\
\hline 42 & ZC2 (TNIK) & TRAF2 and NCK-interacting protein-serine kinase & -15.65 & 0.017 \\
\hline 43 & HO1 (HO; HMOX1) & Heme oxygenase 1 & -16.09 & 0.025 \\
\hline 44 & WNK3 (PRKWNK3) & Protein-serine/threonine kinase WNK3 & -17.01 & 0.002 \\
\hline 45 & HDAC5 & Histone deacetylase 5 & -17.02 & 0.039 \\
\hline 46 & GSK3 Beta (GSK3b) & Glycogen synthase kinase- 3 beta & -17.07 & 0.014 \\
\hline 47 & PFTAIRE-1 (CDK14) & Cyclin-dependent kinase 14 & -17.10 & 0.013 \\
\hline 48 & CDK10 & Cyclin-dependent protein-serine kinase 10 & -17.67 & 0.009 \\
\hline 49 & PRKACA/B (PKACA/B) & cAMP-dependent protein kinase catalytic subunit alpha & -18.32 & 0.041 \\
\hline 50 & CaMK2d & $\begin{array}{l}\text { Calcium/calmodulin-dependent protein } \\
\text { kinase type II subunit delta }\end{array}$ & -18.73 & 0.001 \\
\hline 51 & PKG2 (PRKG2) & cGMP-dependent protein kinase 2 & -19.65 & 0.003 \\
\hline 52 & CaMK2b (CaMKIIb) & $\begin{array}{l}\text { Calcium/calmodulin-dependent protein } \\
\text { kinase type II subunit beta }\end{array}$ & -19.70 & 0.025 \\
\hline 53 & Yes & $\begin{array}{l}\text { Yamaguchi sarcoma proto-oncogene-encoded } \\
\text { tyrosine kinase }\end{array}$ & -20.05 & 0.010 \\
\hline 54 & CDK9 & Cyclin-dependent protein-serine kinase 9 & -20.26 & 0.009 \\
\hline 55 & WNK4 (PRKWNK4) & Protein-serine/threonine kinase WNK4 & -21.30 & 0.029 \\
\hline 56 & HspBP1 & Hsp70-binding protein 1 & -22.08 & 0.000 \\
\hline 57 & COX2 & Prostaglandin G/H synthase 2 & -23.06 & 0.044 \\
\hline 58 & Cyclin D2 (CCND2) & Cyclin D2 & -23.30 & 0.011 \\
\hline 59 & ErbB3 (HER3) & Tyrosine kinase-type cell surface receptor HER3 & -23.67 & 0.048 \\
\hline 60 & AurKB (Aurora B, AIM-1, ARK-2) & Aurora Kinase B (Protein-serine/threonine kinase 12) & -25.21 & 0.027 \\
\hline 61 & Chk2 (CHEK2) & Checkpoint protein-serine kinase 2 & -25.31 & 0.006 \\
\hline 62 & I1PP2A & $\begin{array}{l}\text { Acidic leucine-rich nuclear phosphoprotein } \\
\qquad 32 \text { family member A }\end{array}$ & -30.59 & 0.032 \\
\hline 63 & ERK1 (MAPK3; ERT2; p44-MAPK) & $\begin{array}{l}\text { Extracellular regulated protein-serine kinase } 1 \\
\qquad(\mathrm{p} 44 \text { MAP kinase) }\end{array}$ & -34.30 & 0.005 \\
\hline 64 & HO2 (HMOX2) & Heme oxygenase 2 & -50.03 & 0.043 \\
\hline 65 & Hip & Hsc70-interacting protein & -61.61 & 0.002 \\
\hline
\end{tabular}




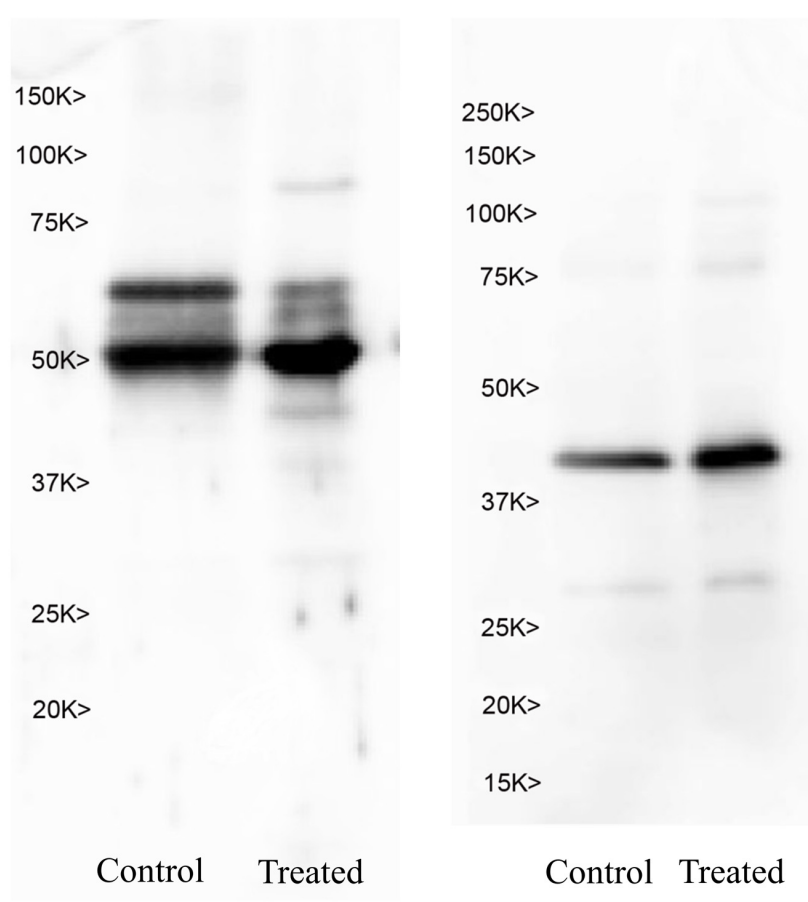

(a)

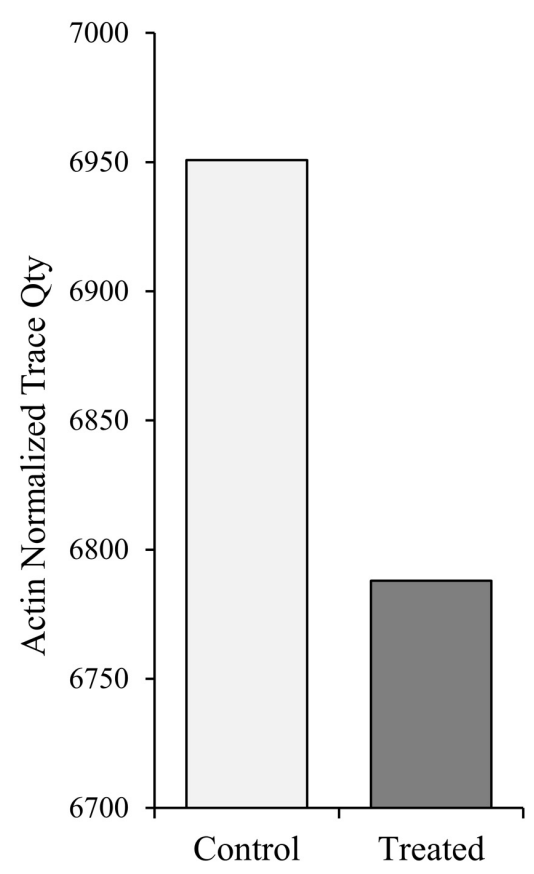

(c)

Figure S1. (a) Representation of western blotting with A11 antibody specific for A $\beta$ oligomers (MW $\sim 50 \mathrm{kDa})$, (b) Control blotting with beta-actin ( $\mathrm{MW} \sim 41 \mathrm{kDa}$ ), (c) Bar chart showing the actin normalized trace quantities of A11 immunopositivity in the control and experimental groups. 